\title{
A Melatonin Treatment Delays Postharvest Senescence, Maintains Quality, Reduces Chilling Injury, and Regulates Antioxidant Metabolism in Mango Fruit
}

\author{
Renu Bhardwaj $\mathbb{D}^{1,2}$ Sunil Pareek ${ }^{10},{ }^{1}$ Saravanan Mani $\mathbb{D}^{3},{ }^{3}$ \\ J. Abraham Domínguez-Avila ${ }^{D},{ }^{4}$ and Gustavo A. González-Aguilar (i) ${ }^{4}$ \\ ${ }^{1}$ Department of Agriculture and Environmental Sciences, \\ National Institute of Food Technology Entrepreneurship and Management, Kundli, Sonepat, Haryana 131028, India \\ ${ }^{2}$ Department of Biosciences, School of Basic and Applied Sciences, Galgotias University, Greater Noida, \\ Uttar Pradesh 203201, India \\ ${ }^{3}$ Department of Basic and Applied Sciences, National Institute of Food Technology Entrepreneurship and Management, Kundli, \\ Sonepat, Haryana 131028, India \\ ${ }^{4}$ Centro de Investigación en Alimentación y Desarrollo A. C., Carretera Gustavo Enrique Astiazarán Rosas No. 46, \\ Col. La Victoria, Hermosillo 83304, Mexico
}

Correspondence should be addressed to Sunil Pareek; sunil_ciah@yahoo.co.in

Received 11 December 2021; Revised 12 January 2022; Accepted 13 January 2022; Published 30 January 2022

Academic Editor: Encarna Aguayo

Copyright ( $) 2022$ Renu Bhardwaj et al. This is an open access article distributed under the Creative Commons Attribution License, which permits unrestricted use, distribution, and reproduction in any medium, provided the original work is properly cited.

\begin{abstract}
The effects of an exogenous application of various concentrations and dipping duration of melatonin (MT) treatment on postharvest senescence, quality, chilling tolerance, and antioxidant metabolism of mango fruit cv. "Dashehari" were examined. Fruits were treated with three concentrations of MT $(50,100$, or $150 \mu \mathrm{M})$, each applied for three times $(60,90$, or $120 \mathrm{~min})$, followed by storage at $5 \pm 1^{\circ} \mathrm{C}$. The MT concentration of $100 \mu \mathrm{M}$ with a dipping duration of 120 min was efficient in reducing the chilling injury and maintaining the quality of mango fruit for $28 \mathrm{~d}$. Effects of this treatment were due to its effectiveness in reducing metabolic activity, specifically, respiration rate and ethylene production, resulting in higher firmness, titratable acidity, and ascorbic acid content and lower weight loss, total soluble solids, $\mathrm{pH}$, and total soluble solid: acidity ratio. Moreover, it maintained a higher concentration of total phenolics and total flavonoids, as well as antioxidant capacity (2,2-diphenyl-1picrylhydrazyl and cupric reducing antioxidant power assays), as compared to other treatments. This was further confirmed with higher activities of antioxidant enzymes superoxide dismutase and catalase and membrane stability (according to a lower malondialdehyde content and lipoxygenase activity). Thus, our data show that a $100 \mu \mathrm{M}$ MT administered for 120 min appears to be the most appropriate treatment to maintain the quality of mango fruits stored at chilling temperatures.
\end{abstract}

\section{Introduction}

Mango (Mangifera indica) is one of the most nutritive and commonly consumed fruits in tropical and subtropical regions. Its attractive color and aroma, rich flavor, and high nutritional value have made some authors refer to it as the "king of fruits" [1]. Mango is an excellent source of bioactive compounds and nutrients like minerals, provitamin A, carotenoids, ascorbic acid, phenolic compounds, and various other antioxidants [1]. Mango is a climacteric fruit that ripens quickly at ambient temperature, due to its high respiration rate and ethylene production, consequently having a short shelf life of only 5 to 6 days under this condition. Seasonal availability further restricts its marketability to only a few days, although this period can be extended with low-temperature storage at around $13^{\circ} \mathrm{C}$. However, the temperature must be carefully regulated, since signs of chilling injury (CI) begin to develop if fruits are 
stored at $<13^{\circ} \mathrm{C}$ [2]. The major signs of CI include peel discoloration in the form of darkening or blackening, pitting, and abnormal ripening, while their severity becomes more prominent when fruits are transferred to room temperature after low-temperature storage [3].

Various studies have shown that CI in mango can be alleviated to some extent and with some constraints. For example, treatments of chitosan and polyamine spermidine [4] and nitric oxide [5] resulted in low ethylene and $\mathrm{CO}_{2}$ production but also induced poor color development. Ethrel [6], low-temperature conditioning [7], and methyl jasmonate [8] have resulted in increased ripening, while limited CI control has been reported with treatments of oxalic and salicylic acids [9].

Melatonin (N-acetyl-5-methoxytryptamine, MT) has the same auxin function as the hormone indole-3-acetic acid, due to their similarity in biosynthetic pathways [10]. MT has been shown to regulate the stress response in plants through its endogenous accumulation [11], increasing enzymatic and nonenzymatic antioxidant system [12], and promotion of $\gamma$-aminobutyric acid (GABA) shunt pathway activity [13]. MT also stimulates the activity of the oxidative pentose phosphate pathway [14], decreases biosynthesis of ethylene and cell wall degradation [15], and maintains higher nitric oxide, polyamine, and proline concentrations [16], all of which mitigate the development of CI signs.

Exogenous MT applications have been recently studied in order to determine their effects on postharvest physiological characteristics and shelf life of various fresh commodities. For example, $\mathrm{Hu}$ et al. [17] report that a postharvest immersion treatment of MT ( 0.05 to $0.5 \mathrm{mM})$ on banana fruit suppressed ethylene biosynthesis and hydrolysis of starch, findings that were associated with delayed ripening. Zhai et al. [15] observed that an MT (0.1 mM) immersion treatment suppressed the expression of PcACS1, $P c A C O 1$, and $P c P G$ in pear fruit, which also delayed ripening and decreased occurrence of physiological issues. There are a couple of opposing perceptions to those acquired from bananas and pears. For instance, Sun et al. [18] revealed that exogenous MT treatment at $0.05 \mathrm{mM}$ induced the ethylene climacteric and advanced ethylene flagging transduction in tomatoes. In nonclimacteric grapes, the use of exogenous MT $(0.1 \mathrm{mM})$ on unripe berries promoted aging by increasing the endogenous ethylene levels [19]. These contrasting discoveries suggest that the effects of MT on ripening and senescence are likely to vary among various agricultural commodities.

To the best of our knowledge, only a few comparable studies are available in mango fruit. For example, a $1 \mathrm{mM}$ MT treatment preserved certain postharvest quality parameters, by inhibiting phenolic oxidation and stimulating cellular integrity during cold storage of about a month at $15^{\circ} \mathrm{C}$ [20]. Application of MT $(0.5 \mathrm{mM}$ for $1 \mathrm{~h})$ to "Guifei" mangoes effectively delayed the changes in ripening parameters like firmness, pulp color, $\beta$-carotene levels, total soluble solids (TSS), titratable acidity (TA), and respiration rate. MT delayed climacteric ethylene production and 1aminocyclopropane-1-carboxylic acid (ACC) levels in mango fruit during storage at $25^{\circ} \mathrm{C}$. However, to the best of our knowledge there is no study found with regard to the optimization of MT concentration and impact on CI, postharvest physiology, quality, and shelf life of mango fruit stored at a cold temperature of $5 \pm 1^{\circ} \mathrm{C}$.

The objective of the present study was to find out the optimum concentration and dipping duration applied to mango cv. "Dashehari" stored at $5 \pm 1^{\circ} \mathrm{C}$, which can delay senescence, maintain postharvest quality, alleviate CI, and exert effects on its antioxidant metabolism. The assessment of the best combination of concentration and dipping duration was decided on the basis of postharvest physiological, quality, and ripening parameters, enzymatic and nonenzymatic antioxidant activities, and effects on signs of CI.

\section{Materials and Methods}

2.1. Fruits and Treatment. Mango cv. "Dashehari" fruits at physiological maturity but unripened stage (full shoulder development, firmness $29 \pm 1$ Newton at the time of harvest, however, data presented here is after $3 \mathrm{~d}$ of shelf life) were hand-harvested, from an orchard of a local producer in Sonepat, Haryana, India. Fruits were transported within $1 \mathrm{~h}$ after harvest to the postharvest laboratory via cargo vehicle, under controlled temperature $\left(20^{\circ} \mathrm{C}\right)$. Total 1200 fruits were used, which were free from apparent defects and injuries and of homogenous size and maturity. They were disinfected by dipping in a $1 \%(\mathrm{v} / \mathrm{v})$ sodium hypochlorite solution for $2 \mathrm{~min}$, rinsed with distilled water, shade-dried, and then randomly divided into 10 groups $(n=120)$. Fruits from the first group were dipped in distilled water (control), while the remaining ones were treated with different MT concentrations $(50,100$, or $150 \mu \mathrm{M})$ and dipping durations $(90,120$, or $150 \mathrm{~min}$ ), under the low light condition at $25 \pm 1^{\circ} \mathrm{C}$. The range of melatonin concentration around $100 \mu \mathrm{M}$ was decided as per the previous studies done by Zhai et al. [15], Cao et al. [21], Gao et al. [22], Aghdam et al. [23], and Zhu et al. [24]. The dipping duration was considered in the range of 1 and $2 \mathrm{~h}$ in combination with the above-mentioned MT concentrations. Therefore, on the basis of previous studies of $\mathrm{Hu}$ et al. [17], Cao et al. [21], Aghdam et al. [23], and the recent study done with mango fruit by Liu et al. [25], we have chosen three dipping durations for exogenous MT treatment. In brief, the remaining groups were dipped in $50 \mu \mathrm{M}$ for $90 \mathrm{~min}$ (T1), $50 \mu \mathrm{M}$ for $120 \mathrm{~min}$ (T2), $50 \mu \mathrm{M}$ for $150 \mathrm{~min}$ (T3), $100 \mu \mathrm{M}$ for $90 \mathrm{~min}$ (T4), $100 \mu \mathrm{M}$ for $120 \mathrm{~min}$ (T5), $100 \mu \mathrm{M}$ for $150 \mathrm{~min}$ (T6), $150 \mu \mathrm{M}$ for $90 \mathrm{~min}$ (T7), $150 \mu \mathrm{M}$ for $120 \mathrm{~min}$ (T8), and $150 \mu \mathrm{M}$ for $150 \mathrm{~min}$ (T9). After removal from distilled water or MT solution, fruits were airdried for $2 \mathrm{~h}$ at room temperature and immediately stored at $5 \pm 1^{\circ} \mathrm{C}$ (relative humidity $85-90 \%$ ). Weight and color measurements of fruits from each group were taken at $7 \mathrm{~d}$ intervals after being moved out of cold storage. All other parameters were measured at $7 \mathrm{~d}$ intervals, followed by a $3 \mathrm{~d}$ shelf life at room temperature of $25^{\circ} \mathrm{C}$.

2.2. Chilling Injury (CI) Index. CI index was determined as described by Concellón et al. [26] with some modifications. The symptoms considered for CI index assessment include 
discoloration of the skin, greyish scald, poor flavor, or pitting in mangoes. CI index was assessed based on the injured area on a scale of 0 to 5 where $0=$ no injury, $1=1$ to $20 \%, 2=21$ to $40 \%, 3=41$ to $60 \%, 4=61$ to $80 \%$, and $5=81$ to $100 \%$. CI index was expressed as percent (\%) and calculated in triplicate (where each replicate consists of 10 fruits) according to the following formula:

CI index $=\frac{\sum(\text { CII rank score } \times \text { number of fruits in each rank scale })}{\text { total number of fruits observed }}$.

\subsection{Ethylene Production and Respiration Rate. An airtight} glass container $(800 \mathrm{~mL})$ was used to quantify ethylene production, which was measured in the container's headspace by piercing the probe of an ethylene analyzer (Bioconservacion, Spain) into it. The measurements of the apparatus range from 0 to $100 \mathrm{ppm}$ through the septum fixed to the container lid. Ethylene production was measured after $2 \mathrm{~h}$ at $20^{\circ} \mathrm{C}$ in triplicate $(n=3)$ and was expressed as $\mathrm{nmol} \mathrm{kg} \mathrm{kg}^{-1} \mathrm{~s}^{-1}$ by using the following formula:

ethylene production $=\frac{\text { ethylene produced } \times \text { head space volume }}{\text { fruit weight }(\mathrm{kg}) \times \text { time }(\mathrm{s})}$.

Respiration rate was measured in triplicate $(n=3)$. The assessment was done by piercing the probe of an autogas analyzer (PBI Dansensor, Denmark) into the container described for ethylene production, through the rubber septum fixed on the lid of the container. Measurements were taken after $2 \mathrm{~h}$ at $20^{\circ} \mathrm{C}$, and production of $\mathrm{CO}_{2}$ was expressed in $n m o l \mathrm{~kg}^{-1} \mathrm{~s}^{-1}$ by using the following formula:

respiration rate $=\frac{\mathrm{CO}_{2} \text { produced } \times \text { head space volume }}{\text { fruit weight }(\mathrm{kg}) \times \text { time }(\mathrm{s})}$.

\subsection{Physicochemical Evaluations}

2.4.1. Weight Loss. Weight loss was calculated as the difference between the initial and final weight of fruit (10 fruit) at weekly intervals. The results were expressed in terms of percentage (\%) of initial fresh weight.

2.4.2. Firmness. Fruit firmness was measured using a texture analyzer (TA.HDplus, Stable Micro Systems, UK) equipped with a $2 \mathrm{~mm}$ diameter probe, which was set to a pretest speed of $1.5 \mathrm{~mm} \mathrm{~s}^{-1}$, test speed of $0.5 \mathrm{~mm} \mathrm{~s}^{-1}$, and posttest speed of $10 \mathrm{~mm} \mathrm{~s}^{-1}$. Measurements were taken to a penetration depth of $5 \mathrm{~mm}$ at two opposite points in the equatorial region in triplicate, where each replicate consists of 3 fruits. Results were expressed in Newton $(\mathrm{N})$.

2.4.3. Color. Peel color was determined based on the $L^{*}, a^{*}$, and $b^{*}$ color system, where the value of $L^{*}$ represents darkness or lightness, the value of $a^{*}$ represents greenness $(-)$ or redness $(+)$, and the value of $b^{*}$ represents yellowness $(+)$ or blueness $(-)$. These parameters were measured using a hand-held CR-400 colorimeter (Konica Minolta Sensing Inc., Osaka, Japan), based on the CIE system. Each fruit was measured on the equatorial axis of two opposite sides and observations were taken in triplicate with 3 fruits in each replicate. The values of $a^{*}$ and $b^{*}$ were used to calculate chroma and hue angle, according to the following formula:

$$
\begin{aligned}
& \text { chroma }=\left(a^{* 2}+b^{* 2}\right)^{1 / 2}, \\
& \text { hue angle }=\tan ^{-1} \frac{b^{*}}{a^{*}} .
\end{aligned}
$$

2.4.4. Total Soluble Solids (TSSs), Titratable Acidity (TA), TSS/TA Ratio, and $p H$. TSSs were measured in fruit pulp that was squeezed through a muslin cloth. A drop of filtered juice was analyzed using a hand-held refractometer (Atago, Japan) at $20^{\circ} \mathrm{C}$ and expressed as percent (\%) in triplicate, with 3 fruits in each replication. The method for the determination of titratable acidity (TA) was based on the AOAC [27]. For this, $10 \mathrm{~g}$ of mango pulp was homogenized (IKA T18 Digital Ultra-Turrax, Cole-Parmer, India) in $100 \mathrm{~mL}$ of distilled water and filtered. Afterward, $10 \mathrm{~mL}$ of the filtrate was titrated against $0.1 \mathrm{~N} \mathrm{NaOH}$ after the addition of $1 \%(\mathrm{v} / \mathrm{v})$ phenolphthalein. Titration was performed until the endpoint (appearance of light pink color) was reached in triplicate $(n=3)$. The TA was expressed as percent $(\%)$. The ratio of TSS-to-TA (TSS/TA) was determined by dividing the value of TSS by that of TA. The $\mathrm{pH}$ of mango juice was measured with a $\mathrm{pH}$ meter (Cyberscan, Eutech Instruments, Canada) calibrated with standard buffers of pH 7 and 4 .

2.5. Ascorbic Acid. The content of ascorbic acid in mango pulp was determined according to the method of Malik and Zora [28], with minor modifications. Frozen pulp (0.5 g) was homogenized (IKA T18 Digital Ultra-Turrax, Cole-Parmer, India) with $5 \mathrm{~mL}$ of $6 \%(\mathrm{w} / \mathrm{v})$ metaphosphoric acid (MPA) containing $0.18 \%(\mathrm{w} / \mathrm{v})$ ethylene diamine tetra-acetic acid (EDTA). The homogenate was centrifuged (3-18KS, Sigma, Germany) at $10,000 \mathrm{~g}$ for $10 \mathrm{~min}$ at $4^{\circ} \mathrm{C}$, and the supernatant was used for further analysis. The reaction mixture consisted of $0.1 \mathrm{~mL}$ supernatant solution, $1 \mathrm{~mL}$ of $3 \%(\mathrm{w} / \mathrm{v}) \mathrm{MPA}$, and $1 \mathrm{~mL}$ of $10 \%(\mathrm{v} / \mathrm{v})$ Folin Ciocalteu reagent (FCR), measured at $760 \mathrm{~nm}$ on a spectrophotometer (Specord200plus, Analytik Jena, Germany). Results were expressed as $\mathrm{g} \mathrm{kg}^{-1}$ of fresh weight (FW) in triplicate with 3 fruits in each replication, in accordance with a standard curve of ascorbic acid.

2.6. Malondialdehyde (MDA). The main product of lipid peroxidation, i.e., malondialdehyde (MDA), was measured according to the procedure described by Jincy et al. [29]. Frozen pulp $(0.2 \mathrm{~g})$ was homogenized (IKA T18 Digital Ultra-Turrax, Cole-Parmer, India) in $0.1 \%(\mathrm{w} / \mathrm{v})$ trichloroacetic acid (TCA), followed by centrifugation (3-18KS, Sigma, Germany) at $10,000 \mathrm{~g}$ for $10 \mathrm{~min}$ at $4^{\circ} \mathrm{C}$. The reaction mixture consisted of $0.3 \mathrm{~mL}$ supernatant and $1.2 \mathrm{~mL}$ of $0.5 \%$ $(\mathrm{w} / \mathrm{v})$ thiobarbituric acid (TBA) prepared in 20\% (w/v) TCA and was incubated for $30 \mathrm{~min}$ at $95^{\circ} \mathrm{C}$. After this time, the reaction was stopped by submerging the tube in an ice bath for $5 \mathrm{~min}$. The cold tubes were centrifuged (3-18KS, Sigma, 
Germany) at $10,000 \mathrm{~g}$ for $10 \mathrm{~min}$ at ambient temperature. The absorbance of the supernatants was measured at $532 \mathrm{~nm}$ with a spectrophotometer (Specord200plus, Analytik Jena, Germany), from which the nonspecific absorbance at $600 \mathrm{~nm}$ was then subtracted. The concentration of MDA was expressed in $\mathrm{mM} \mathrm{kg}^{-1} \mathrm{FW}$ through the mean of triplicates (each replication consists of 3 fruits), using $155 \mathrm{mmol}^{-1}$ $\mathrm{cm}^{-1}$ as extinction coefficient.

2.7. Extraction Procedure for Total Phenolic Content, Total Flavonoid Content, and Antioxidant Activity. Fruit tissues (peel or pulp) were extracted according to Castro-Concha et al. [30], with some modifications. One gram of frozen tissue was extracted with $10 \mathrm{~mL}$ of $80 \%$ (v/v) ethanol, followed by centrifugation (3-18KS, Sigma, Germany) at $10,000 \mathrm{~g}$ for $20 \mathrm{~min}$ at $4^{\circ} \mathrm{C}$. The clear supernatant was used as a crude extract for the determination of total phenolic content (TPC), total flavonoid content (TFC), and antioxidant activity (AA).

2.7.1. Total Phenolic Content (TPC). TPC of mango tissues (peel or pulp) was determined according to Singleton and Rossi [31], with some modifications. The reaction mixture consisted of $0.1 \mathrm{~mL}$ crude extract and $1 \mathrm{~mL}$ of $10 \%$ (v/v) FCR, to which $1 \mathrm{~mL}$ of $15 \%(\mathrm{w} / \mathrm{v})$ sodium carbonate was added after $2 \mathrm{~min}$ of room temperature incubation. A subsequent $90 \mathrm{~min}$ incubation at room temperature was performed under dark conditions, and the absorbance was recorded at $765 \mathrm{~nm}$ using a spectrophotometer (Specord200plus, Analytik Jena, Germany). Results were expressed in terms of the mean of triplicates with $n=3$, and the result was expressed as $\mathrm{g}$ gallic acid equivalents per $\mathrm{kg}\left(\mathrm{g} \mathrm{GAE} \mathrm{kg}^{-1}\right)$ of FW.

2.7.2. Total Flavonoid Content (TFC). TFC of mango tissues (peel or pulp) was quantified according to the method of Chang et al. [32], with some modifications. Crude extract $(0.1 \mathrm{~mL})$ was added to a reaction mixture that contained $0.1 \mathrm{~mL}$ of $1 \mathrm{M}$ potassium acetate and $10 \%(\mathrm{w} / \mathrm{v})$ aluminum chloride. The volume was made up to $3 \mathrm{~mL}$ by adding $2.8 \mathrm{~mL}$ of distilled water. The solution was incubated for $45 \mathrm{~min}$ at room temperature under dark conditions. Absorbance was then read at $510 \mathrm{~nm}$ on a spectrophotometer (Specord200plus, Analytik Jena, Germany), and the results were expressed as quercetin (QE) $\mathrm{kg}^{-1}$ of FW, calculated using a standard curve of $\mathrm{QE}$ and mean obtained from triplicates $(n=3)$ used to record observation.

2.7.3. Antioxidant Activity (AA). Two in vitro methods were used to determine the AA of free and bound hydrophilic fractions of antioxidants present in mango fruit. AA of the free fraction was determined using the 2,2-diphenyl-1-picrylhydrazyl (DPPH) radical scavenging activity assay, whereas that of the bound fraction was determined using the cupric reducing antioxidant power (CUPRAC) assay. All observations were analyzed in triplicate using 3 fruits in each replication.
2,2-Diphenyl-1-Picrylhydrazyl (DPPH) Radical Scavenging Activity. The DPPH assay was performed according to the method of Larrauri et al. [33], with some modifications. The reaction mixture contained $3.9 \mathrm{~mL}$ of $0.1 \mathrm{mM} \mathrm{DPPH}$ and $0.1 \mathrm{~mL}$ of crude extract and was incubated for $30 \mathrm{~min}$ under darkroom and ambient conditions. The absorbance was then measured at $515 \mathrm{~nm}$ on a spectrophotometer (Specord200plus, Analytik Jena, Germany). Free radical scavenging activity of $\mathrm{DPPH}$ was expressed as a percentage and calculated using the following formula:

$$
\mathrm{DPPH}=\frac{\mathrm{Abs}_{\text {control }}-\mathrm{Abs}_{\text {sample }}}{\mathrm{Abs_{ \text {control } }}},
$$

where control is the reaction mixture with no added sample.

Cupric Reducing Antioxidant Power (CUPRAC). The CUPRAC assay was performed according to the method of Arscott and Tanumihardjo [34], with some modifications. A $0.1 \mathrm{~mL}$ volume of crude extract was added to the reaction mixture, which contained $0.5 \mathrm{~mL}$ of $10 \mathrm{mM}$ cupric chloride solution and the same volume of a $7.5 \mathrm{mM}$ alcoholic neocuproine solution and $1 \mathrm{M}$ ammonium acetate buffer $(\mathrm{pH}$ 7.0). The reaction was incubated for $30 \mathrm{~min}$ under dark conditions at room temperature, and its absorbance was then read at $450 \mathrm{~nm}$ with a spectrophotometer (Specord200plus, Analytik Jena, Germany). Results were expressed as the mass of Trolox equivalents (TE) on an FW basis, which was calculated using a standard curve of Trolox.

\subsection{Enzyme Activity}

2.8.1. Superoxide Dismutase (SOD). Enzyme activity of superoxide dismutase (SOD, EC 1.15.1.1) was calculated according to the method of Kono [35]. For this, $1 \mathrm{~g}$ of fruit tissue was homogenized (IKA T18 Digital Ultra-Turrax, Cole-Parmer, India) with $10 \mathrm{~mL}$ of precooled $\left(4^{\circ} \mathrm{C}\right) 100 \mathrm{mM}$ potassium phosphate buffer $(\mathrm{pH} 7.0)$, followed by centrifugation (3-18KS, Sigma, Germany) at $10,000 \mathrm{~g}$ at $4^{\circ} \mathrm{C}$ for $20 \mathrm{~min}$. The assay tube contained $1.3 \mathrm{~mL}$ sodium carbonate buffer $(50 \mathrm{mM}, \mathrm{pH} 7.0), 0.5 \mathrm{~mL}$ of $96 \mu \mathrm{M}$ nitroblue tetrazolium (NBT), $0.1 \mathrm{~mL}$ of $0.6 \%(\mathrm{v} / \mathrm{v})$ triton-X, and $0.1 \mathrm{~mL}$ of crude extract. A $0.1 \mathrm{~mL}$ of $20 \mathrm{mM}$ hydroxylamine hydrochloride $(\mathrm{pH}$ 6.0) was added to start the reaction, which lasted for $2 \mathrm{~min}$. Enzyme activity was calculated in triplicate, where each replicate consists of 3 fruits and activity is assessed according to the reduction of NBT, which was detected by an increase in absorbance at $540 \mathrm{~nm}$ spectrophotometrically (Specord200plus, Analytik Jena, Germany), and expressed as $\mathrm{U} \mathrm{kg}^{-1}$ protein.

2.8.2. Catalase (CAT). The activity of catalase (CAT, EC 1.11.1.6) was measured according to Aebi [36] with some modifications in a $0.1 \mathrm{~mL}$ enzyme extract volume, which was obtained from $1 \mathrm{~g}$ of fruit tissue homogenized (IKA T18 Digital Ultra-Turrax, Cole-Parmer, India) in precooled $100 \mathrm{mM}$ potassium phosphate buffer ( $\mathrm{pH}$ 7.0). This was added to a mixture containing $0.7 \mathrm{~mL}$ phosphate buffer $(100 \mathrm{mM}, \mathrm{pH} 7.0)$ and $0.6 \mathrm{~mL}$ of $150 \mathrm{mM} \mathrm{H}_{2} \mathrm{O}_{2}$. CAT activity was quantified, 
according to its ability to catalyze the decomposition of $\mathrm{H}_{2} \mathrm{O}_{2}$ into the water and molecular oxygen. Results were determined through the mean obtained from triplicate $(n=3)$ and observation was recorded with a decrease in absorbance at $240 \mathrm{~nm}$ with a spectrophotometer (Specord200plus, Analytik Jena, Germany) and expressed as $\mathrm{U} \mathrm{kg}^{-1}$ protein.

2.8.3. Lipoxygenase (LOX). The activity of lipoxygenase (LOX, EC 1.13.11) was determined according to the method of Todd et al. [37], with some modifications. For this, $1 \mathrm{~g}$ of tissue sample was homogenized (IKA T18 Digital UltraTurrax, Cole-Parmer, India) in $5 \mathrm{~mL}$ of precooled $100 \mathrm{mM}$ Tris- $\mathrm{HCl}$ buffer ( $\mathrm{pH} 7.0)$, which was centrifuged (3-18KS, Sigma, Germany) at $10,000 \mathrm{~g}$ for $20 \mathrm{~min}$ at $4^{\circ} \mathrm{C}$. The supernatant was collected and used as a crude extract. The assay tube contained $1 \mathrm{~mL}$ of standard assay mixture $(40 \mathrm{~mL}$ of $100 \mathrm{mM}$ sodium phosphate buffer with $200 \mu \mathrm{L}$ of Tween 20 and $40 \mu \mathrm{L}$ of linoleic acid) and $0.2 \mathrm{~mL}$ of crude extract. The activity of LOX is calculated with triplicate (involving 3 fruits in each replication) and was expressed as $\mathrm{U} \mathrm{kg}^{-1}$ protein, where $U$ is the amount of enzyme that changes the absorbance at $234 \mathrm{~nm} \mathrm{~min}{ }^{-1}$ spectrophotometrically (Specord200plus, Analytik Jena, Germany).

2.9. Protein Concentration. The protein concentration of the extracts was determined according to the method of Bradford [38], with some modifications. Fruit tissue (1 g) was homogenized (IKA T18 Digital Ultra-Turrax, ColeParmer, India) in $10 \mathrm{~mL}$ of precooled $50 \mathrm{mM}$ of sodium phosphate buffer, containing $2 \mathrm{mM}$ of phenylmethylsulfonyl fluoride (PMSF), $2 \mathrm{mM}$ of polyvinylpolypyrrolidone (PVPP), and $0.5 \mathrm{mM}$ of $\mathrm{MgCl}_{2}$. The homogenate was centrifuged (3-18KS, Sigma, Germany) at $10,000 \mathrm{~g}$ for $20 \mathrm{~min}$ at $4^{\circ} \mathrm{C}$, and the supernatant was used as a crude extract. A $0.1 \mathrm{~mL}$ of extract was then added to the reaction mixture consisting of $5 \mathrm{~mL}$ of Bradford's reagent. After a 5 min incubation period at room temperature, the absorbance was read at $595 \mathrm{~nm}$ with a spectrophotometer (Specord200plus, Analytik Jena, Germany), and protein concentration was calculated with a standard curve of bovine serum albumin (BSA) in triplicate (where each replication consists of 3 fruits).

2.10. Statistical Analysis. Experiments were performed using a completely randomized design (CRD), with three technical replicates. The data are expressed as the average of three measurements \pm standard error (SE). SPSS (version20) software was used to analyze data with a one-way analysis of variance (ANOVA) with a 0.05 probability level. The means were further separated by using the Duncan multiple range post hoc test.

\section{Results}

3.1. Chilling Injury (CI). The signs of CI in the form of blackbrown lesions and pitting were progressive in all groups, but with different degrees of severity (Figure 1(a)). After $7 \mathrm{~d}$ of cold storage $\left(5 \pm 1^{\circ} \mathrm{C}\right)$ plus a $3 \mathrm{~d}$ shelf life period at ambient conditions, most groups had apparent signs of CI, except for T5 $(100 \mu \mathrm{M}$ MT for $120 \mathrm{~min})$. The first sign of CI in this group was observed at $14 \mathrm{~d}$ of storage, followed by $3 \mathrm{~d}$ shelf life under ambient conditions. However, the MT treatment significantly $(p<0.05)$ suppressed the CI index and CI incidence, with the exception of $\mathrm{T} 1(50 \mu \mathrm{M}$ MT for $90 \mathrm{~min})$ (Figure 1(a)). Among all treatments, T5 $(100 \mu \mathrm{M}$ MT for $120 \mathrm{~min})$ was the most effective in reducing CI incidence (Figure 1(b)) and CI index (Figure 1(c)) by 4.16 and 4.47 times, respectively, as compared with the control.

3.2. Respiration Rate and Ethylene Production. In the control group, a climacteric rise in respiration rate (Figure 2(a)) and ethylene production (Figure 2(b)) were observed after $21 \mathrm{~d}$ of cold storage. The MT-treated fruits did not show such a sudden increase at this time, although a continuous rise in both parameters was apparent in MT-treated fruits throughout the observation period of $28 \mathrm{~d}$. Additionally, T5 treatment $(100 \mu \mathrm{M}$ MT for $120 \mathrm{~min})$ was the most effective in reducing both respiration rate and ethylene production at $28 \mathrm{~d}$ of observation, as compared to all other treatments.

\subsection{Physicochemical Properties}

3.3.1. Weight Loss. As a result of increased metabolic activity, weight loss was also progressive during the storage period (Table 1). The control group, T1 $(50 \mu \mathrm{MMT}$ for $90 \mathrm{~min}), \mathrm{T} 2$ (50 $\mu \mathrm{M}$ MT for $120 \mathrm{~min})$, and T6 (100 $\mu \mathrm{M}$ MT for $150 \mathrm{~min}$ ) had weight losses of 9.23, 9.10, 9.27, and 9.20\%, respectively, after $28 \mathrm{~d}$ whereas $\mathrm{T} 3(50 \mu \mathrm{M}$ MT for $150 \mathrm{~min})$, T7 (150 $\mu \mathrm{M}$ MT for $90 \mathrm{~min})$, and T8 (150 $\mu \mathrm{M}$ MT for $120 \mathrm{~min})$ had weight losses of $10.23,10.23$, and $10.00 \%$, respectively. It is noteworthy that T5 (100 $\mu \mathrm{M} \mathrm{MT}$ for $120 \mathrm{~min})$ had the lowest weight loss among all groups, of only $7.90 \%$.

3.3.2. Firmness. Independent of treatment, fruit firmness progressively declined during storage due to the textural changes of the fruit; however, MT-treated fruits maintained relatively higher firmness. Most notably, T5 $(100 \mu \mathrm{M}$ MT for $120 \mathrm{~min})$ had significantly $(p<0.05)$ higher firmness until the end of the storage period (Table 1).

3.3.3. Color. There was a gradual increase in $L^{*}$ and chroma values in the peel of all groups, during the experimental period. However, a nonsignificant $(p<0.05)$ difference was observed in both parameters at $7 \mathrm{~d}$ in all treated groups (Table 2). A continuous rise in hue was observed in T5 (100 $\mu \mathrm{M}$ MT for $120 \mathrm{~min}$ ), while a nonsignificant difference $(p<0.05)$ was observed among the other treatments (Table 2).

3.3.4. Total Soluble Solids (TSS), $p H$, Titratable Acidity (TA), TSS/TA Ratio, and Ascorbic Acid. Results for TSS, pH, TA, TSS/TA, and ascorbic acid are shown in Table 3. The breakdown of carbohydrates that occurs during fruit 

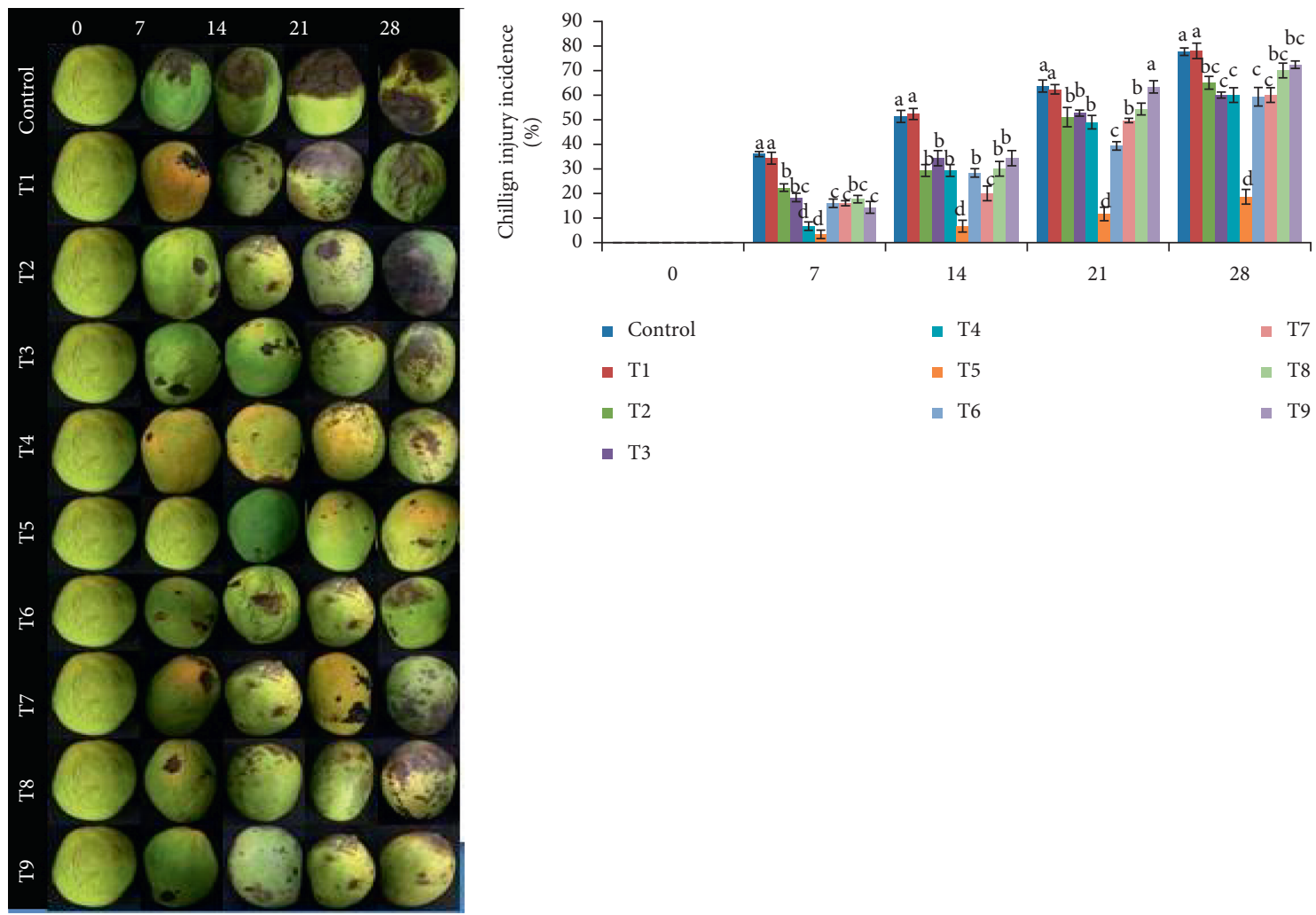

(a)

(b)

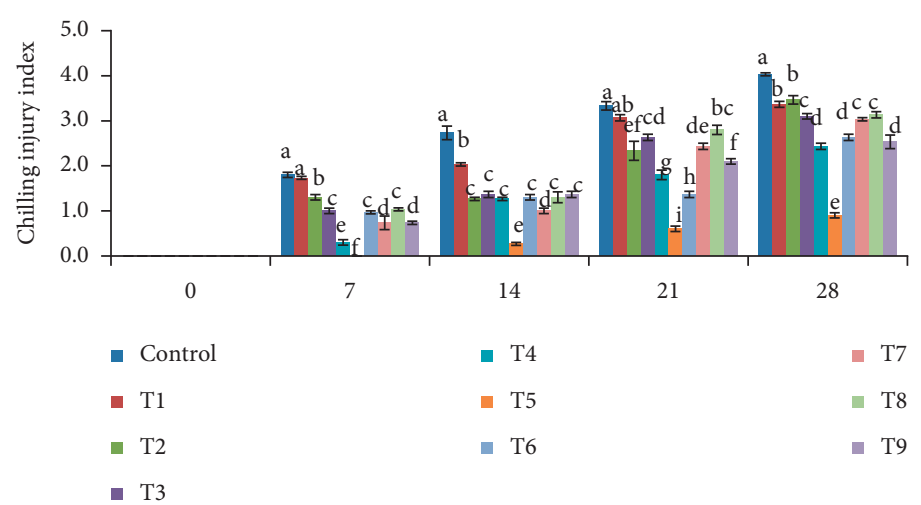

(c)

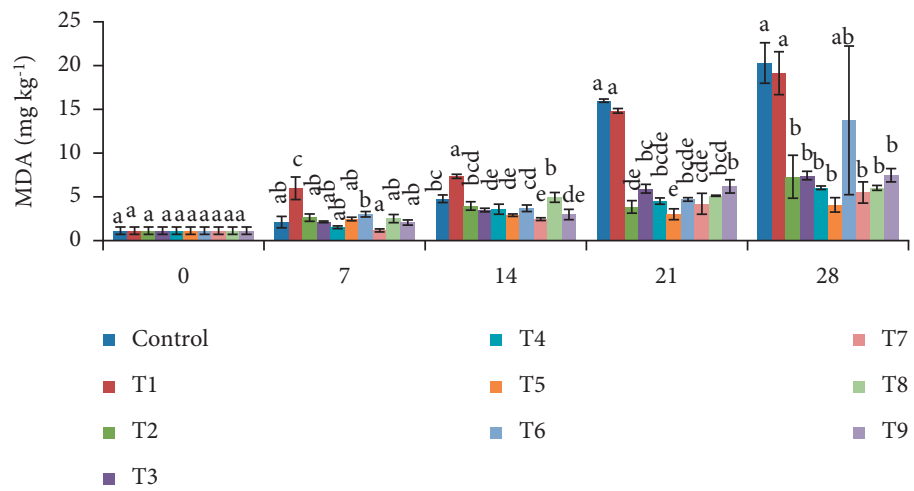

(d)

Figure 1: (a) Representative images, (b) chilling injury (CI) incidence, (c) CI index, and (d) malondialdehyde (MDA) of mango cv. "Dashehari" treated with melatonin (MT), followed by low-temperature storage at $5 \pm 1^{\circ} \mathrm{C}$. Measurements were taken every $7 \mathrm{~d}$ of storage, followed by a $3 \mathrm{~d}$ of shelf life at room temperature. Each value is the mean of three replicates; vertical bars indicate the standard error. Different lowercase letters on the same storage period indicate a significant difference $(p<0.05)$ according to Duncan's multiple range test. The abbreviated treatment details: 0 (control), $50 \mu \mathrm{M}$ for $90 \mathrm{~min}$ (T1), $50 \mu \mathrm{M}$ for $120 \min$ (T2), $50 \mu \mathrm{M}$ for $150 \mathrm{~min}$ (T3), $100 \mu \mathrm{M}$ for $90 \mathrm{~min}$ (T4), $100 \mu \mathrm{M}$ for $120 \mathrm{~min}$ (T5), $100 \mu \mathrm{M}$ for $150 \mathrm{~min}$ (T6), $150 \mu \mathrm{M}$ for $90 \mathrm{~min}$ (T7), $150 \mu \mathrm{M}$ for $120 \mathrm{~min}$ (T8), and $150 \mu \mathrm{M}$ for $150 \mathrm{~min}$ (T9). 


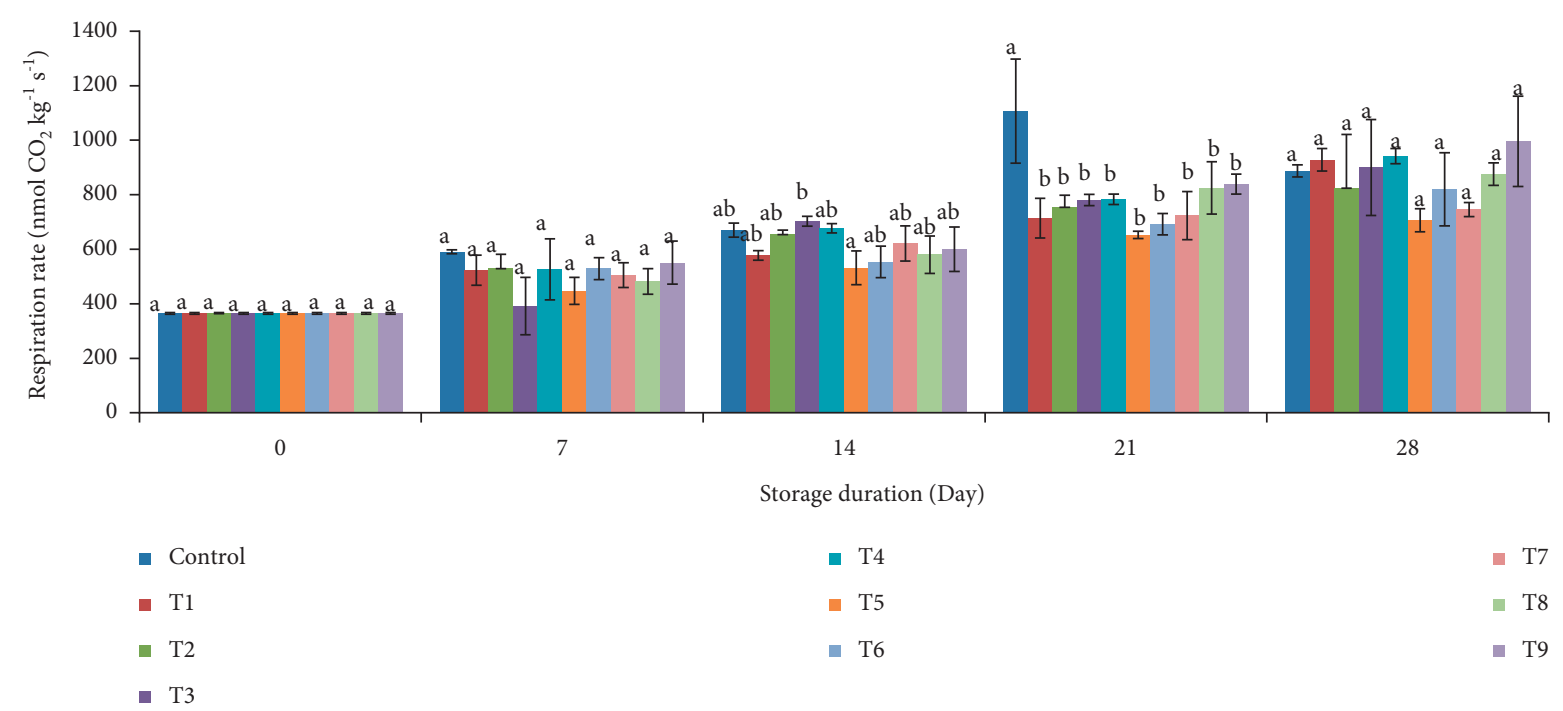

(a)

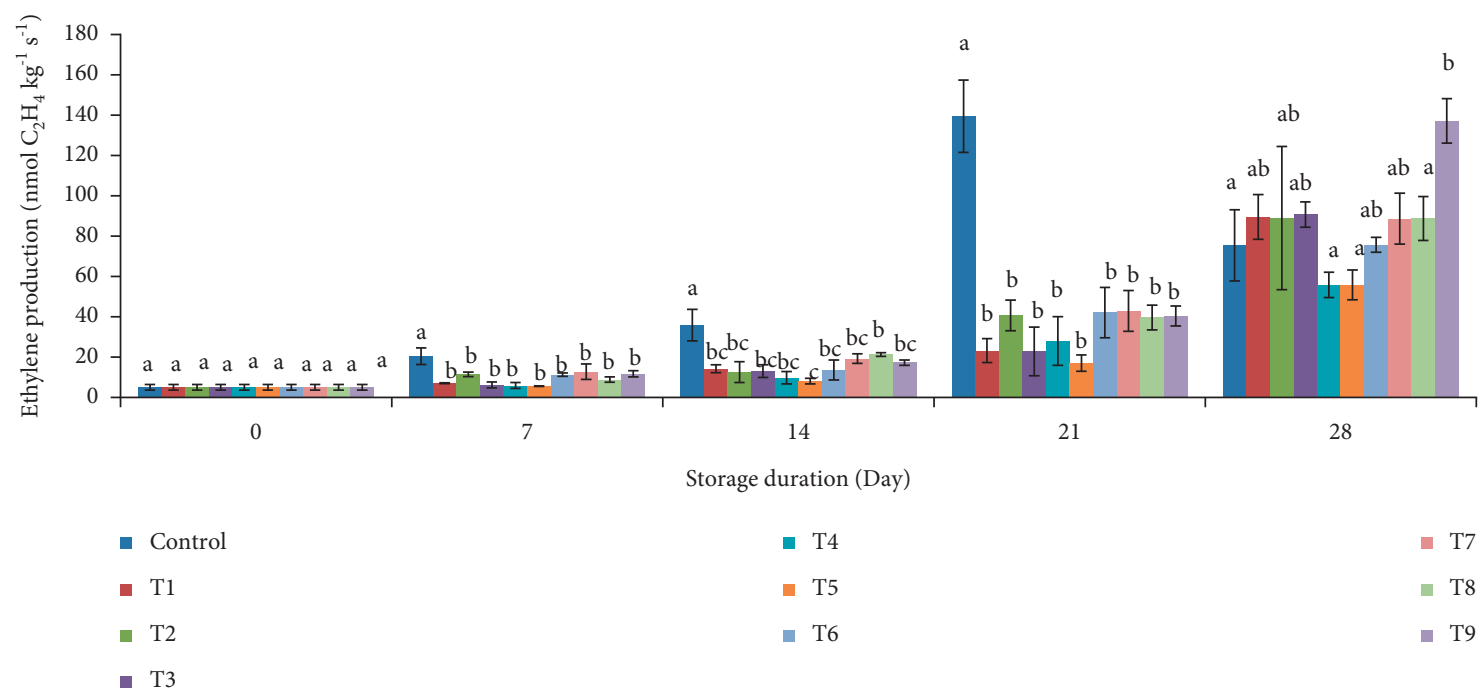

(b)

FIgURE 2: (a) Respiration rate and (b) ethylene production of mango cv. "Dashehari" treated with melatonin (MT), followed by lowtemperature storage at $5 \pm 1^{\circ} \mathrm{C}$. Measurements were taken every $7 \mathrm{~d}$ of storage, followed by a $3 \mathrm{~d}$ of shelf life at room temperature. Each value is the mean of three replicates; vertical bars indicate the standard error. Different lowercase letters on the same storage period indicate a significant difference $(p<0.05)$ according to Duncan's multiple range test. The abbreviated treatment details: 0 (control), $50 \mu \mathrm{M}$ for $90 \mathrm{~min}$ (T1), $50 \mu \mathrm{M}$ for $120 \mathrm{~min}$ (T2), $50 \mu \mathrm{M}$ for $150 \min$ (T3), $100 \mu \mathrm{M}$ for $90 \min$ (T4), $100 \mu \mathrm{M}$ for $120 \min$ (T5), $100 \mu \mathrm{M}$ for $150 \mathrm{~min}$ (T6), $150 \mu \mathrm{M}$ for $90 \mathrm{~min}$ (T7), $150 \mu \mathrm{M}$ for $120 \mathrm{~min}$ (T8), and $150 \mu \mathrm{M}$ for $150 \mathrm{~min}$ (T9).

ripening resulted in an increase in TSS. T5 $(100 \mu \mathrm{M}$ MT for $120 \mathrm{~min}$ ) maintained its TSS value after $28 \mathrm{~d}$ of storage, as compared to other treatments. The advancing maturity was accompanied by a depletion of organic acids like citric acid, which resulted in a documented increase in $\mathrm{pH}$, while the decline in TA was different among all treatments. The TSS/ TA ratio increased with storage time, due to an increase in TSS and decrease in TA values. T5 (100 $\mu \mathrm{M}$ MT for $120 \mathrm{~min})$ group maintained a higher TA and lower TSS/TA ratio throughout the storage period. The concentration of ascorbic acid decreased in all groups during storage, although T5 (MT $100 \mu \mathrm{M}$ for $120 \mathrm{~min}$ ) had a higher concentration, as compared to all other groups.
3.4. Malondialdehyde (MDA). A continuous rise in MDA was apparent in all groups during the storage period. Remarkably, T7 (150 $\mu \mathrm{M}$ MT for $90 \mathrm{~min})$ and T5 $(100 \mu \mathrm{M} \mathrm{MT}$ for $120 \mathrm{~min}$ ) maintained a low MDA concentration after $28 \mathrm{~d}$ of storage (Figure $1(\mathrm{~d})$ ).

3.5. Total Phenolic Content (TPC), Total Flavonoid Content (TFC), and Antioxidant Activity (AA). T5 (100 $\mu \mathrm{M}$ MT for $120 \mathrm{~min}$ ) had a higher TPC and TFC in both peel (Figures 3(a)-3(b)) and pulp (Figures 4(a)-4(b)), as compared to all other groups throughout the $28 \mathrm{~d}$ storage period. Similarly, the AA in the peel (Figures $3(\mathrm{c})-3(\mathrm{~d})$ ) and pulp 


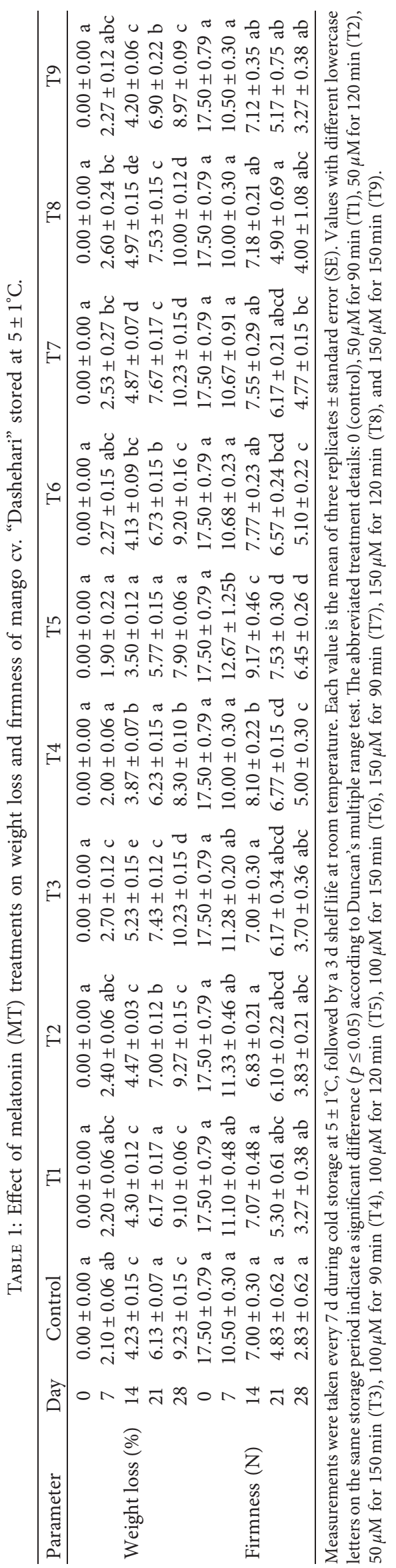




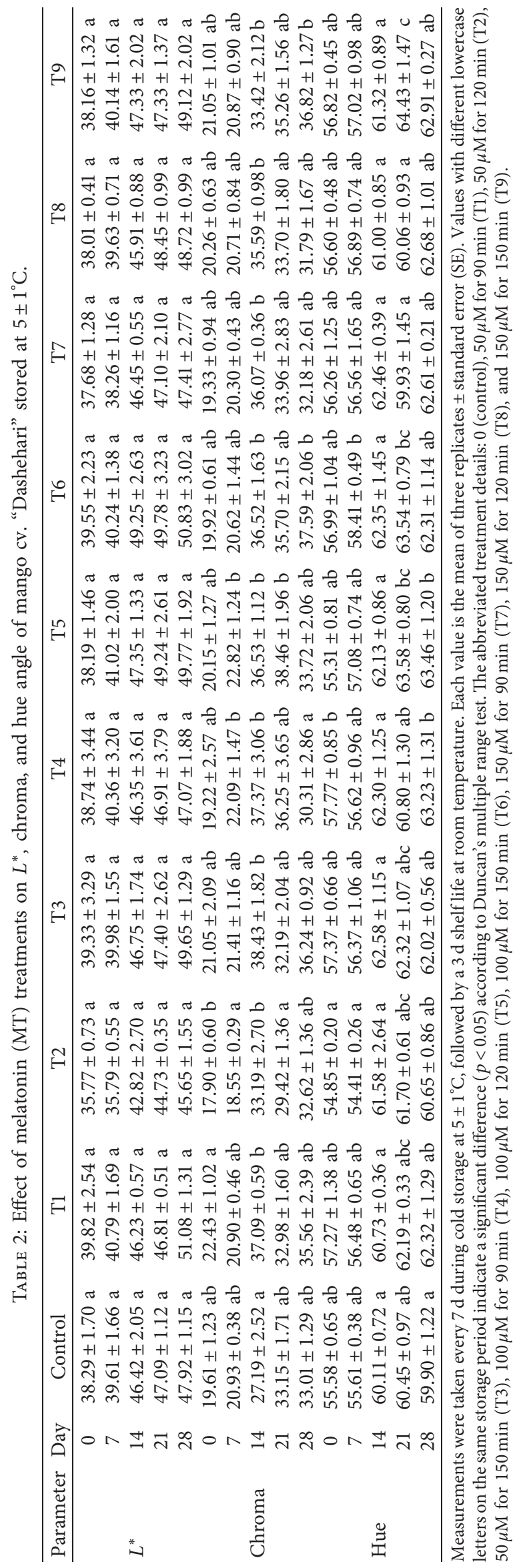




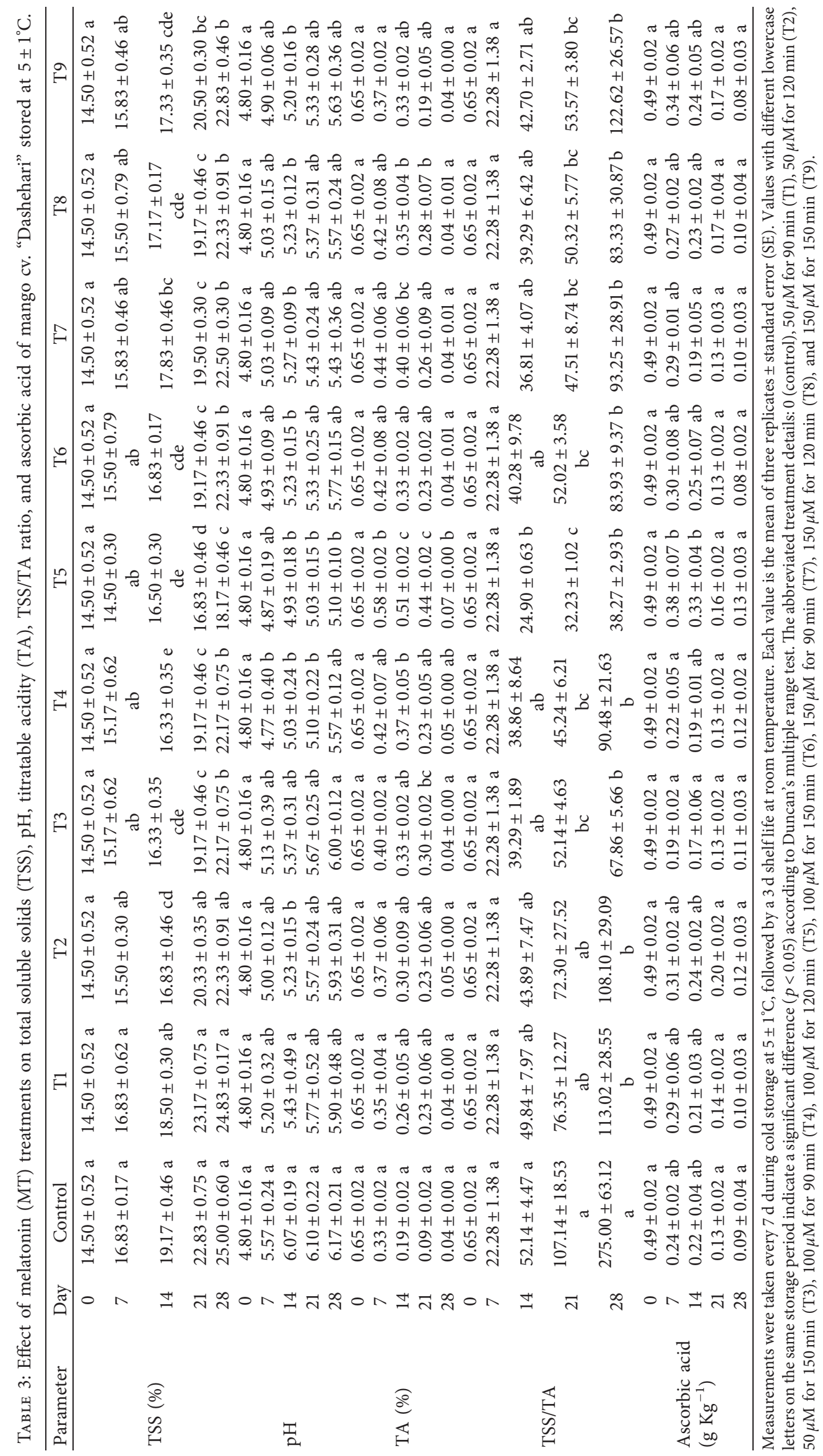




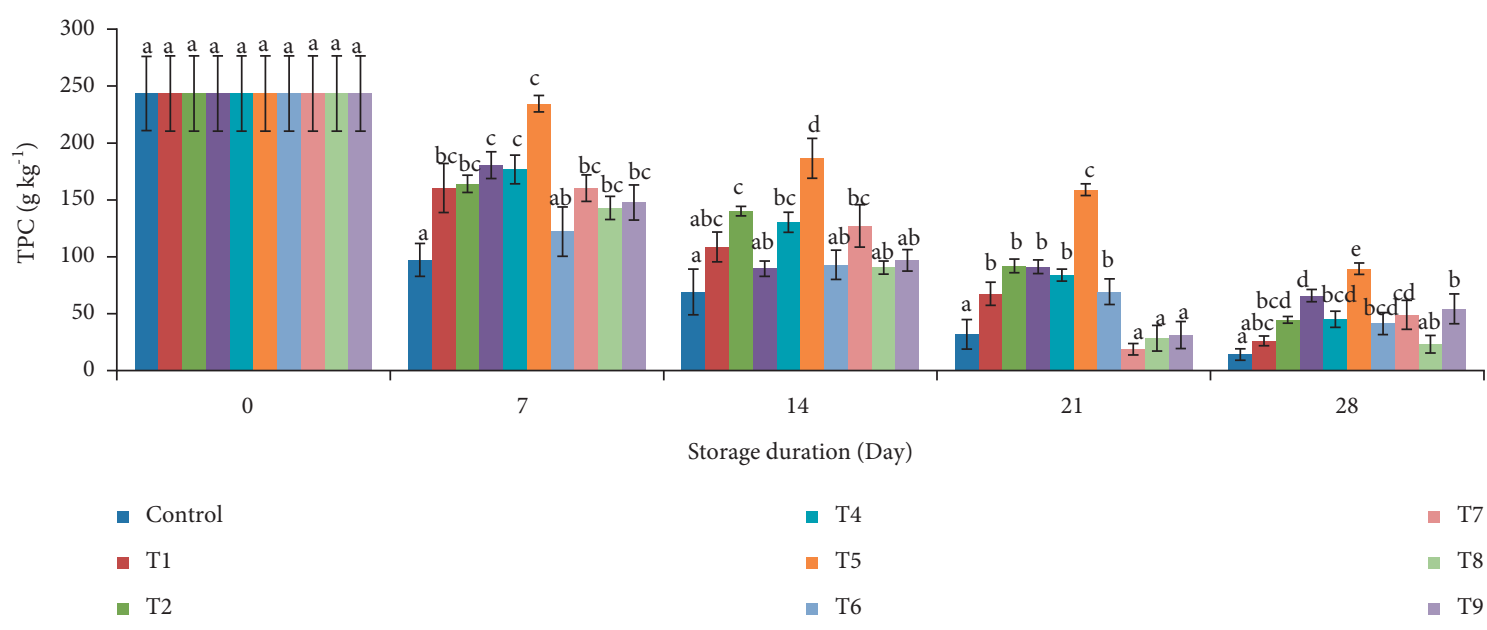

(a)

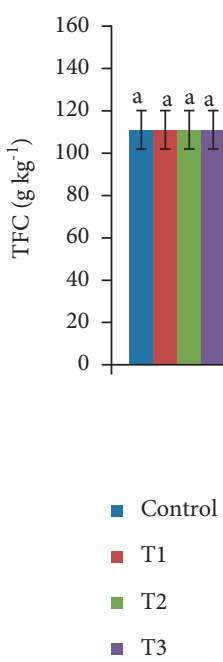

(b)
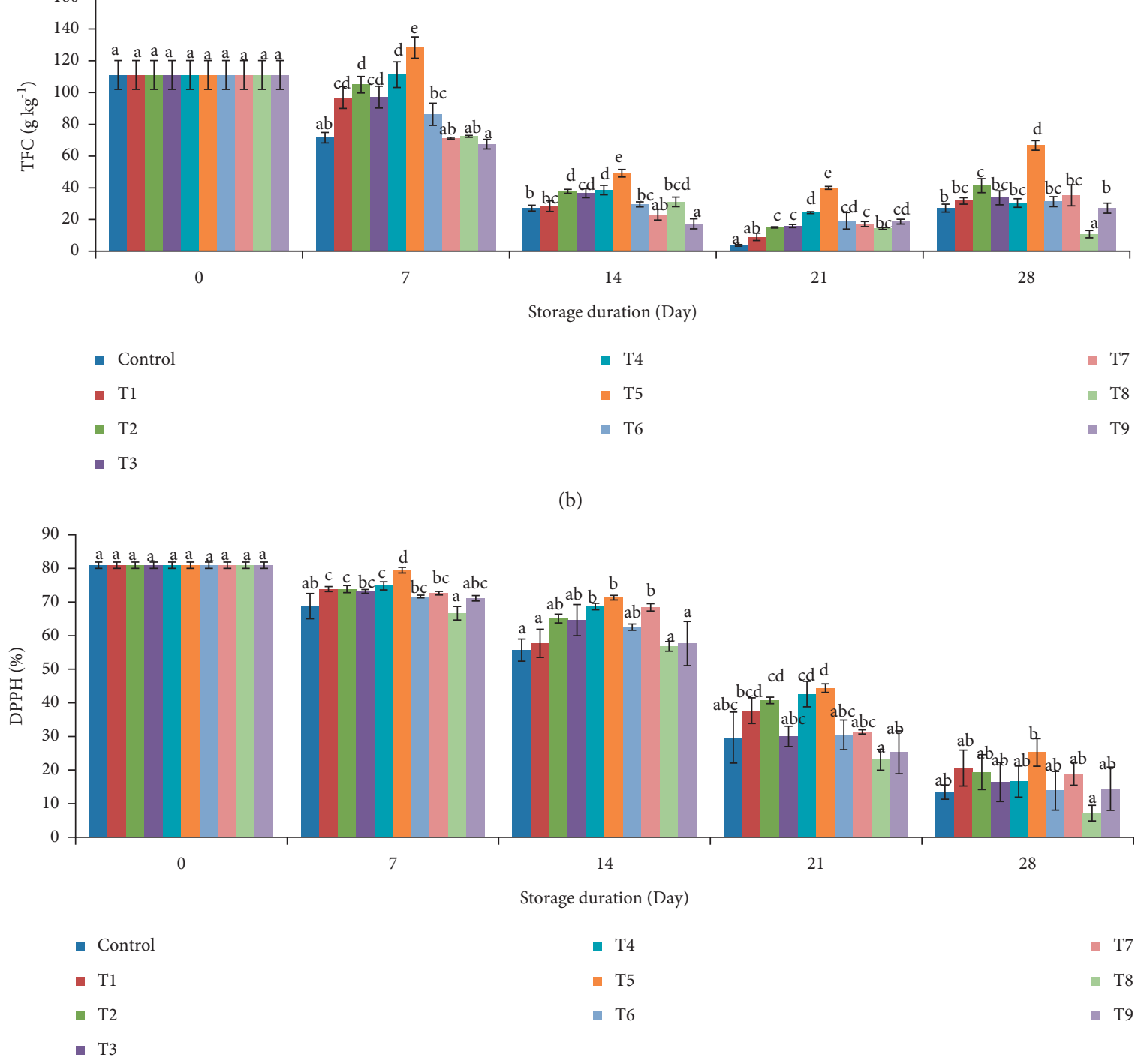

Storage duration (Day)

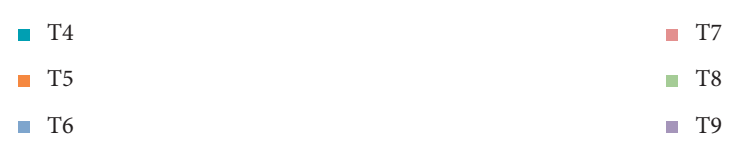

(b)

(c)

Figure 3: Continued. 


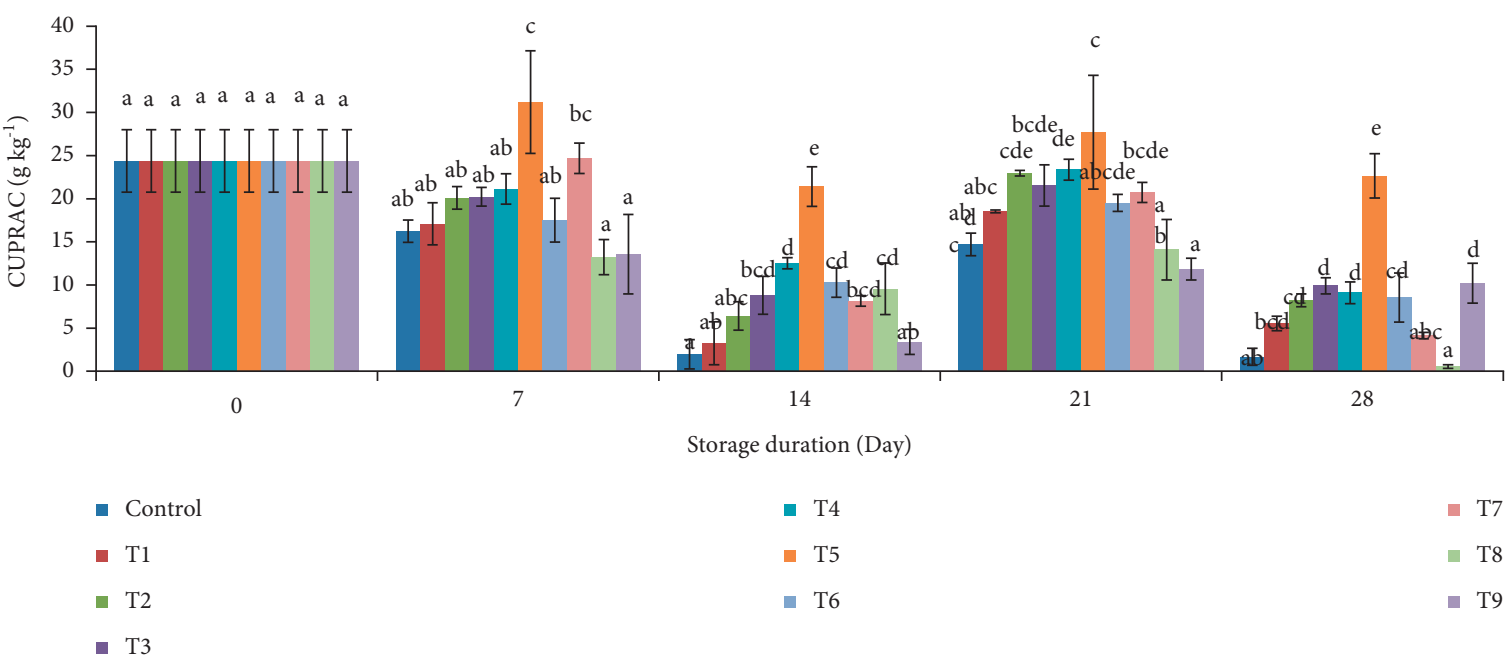

(d)

Figure 3: (a) Total phenolic content (TPC), (b) total flavonoid content (TFC), (c) 2,2-diphenyl-1-picrylhydrazyl (DPPH), and (d) cupric reducing antioxidant power (CUPRAC) of peel of mango cv. "Dashehari" treated with melatonin (MT), followed by low-temperature storage at $5 \pm 1^{\circ} \mathrm{C}$. Measurements were taken every $7 \mathrm{~d}$ of storage, followed by a $3 \mathrm{~d}$ of shelf life at room temperature. Each value is the mean of three replicates; vertical bars indicate the standard error. Different lowercase letters on the same storage period indicate a significant difference $(p<0.05)$ according to Duncan's multiple range test. The abbreviated treatment details: 0 (control), $50 \mu \mathrm{M}$ for $90 \mathrm{~min}(\mathrm{~T} 1), 50 \mu \mathrm{M}$ for $120 \mathrm{~min}$ (T2), $50 \mu \mathrm{M}$ for $150 \mathrm{~min}$ (T3), $100 \mu \mathrm{M}$ for $90 \mathrm{~min}$ (T4), $100 \mu \mathrm{M}$ for $120 \min$ (T5), $100 \mu \mathrm{M}$ for $150 \mathrm{~min}$ (T6), $150 \mu \mathrm{M}$ for $90 \mathrm{~min}$ (T7), $150 \mu \mathrm{M}$ for $120 \mathrm{~min}$ (T8), and $150 \mu \mathrm{M}$ for $150 \mathrm{~min}$ (T9).

(Figures 4(c)-4(d)), as measured with the DPPH and CUPRAC assays, was also higher in T5 (100 $\mu \mathrm{M}$ MT for $120 \mathrm{~min})$.

\subsection{Enzyme Activity}

3.6.1. Superoxide Dismutase (SOD). SOD activity in T5 $(100 \mu \mathrm{M}$ MT for $120 \mathrm{~min})$ increased until $14 \mathrm{~d}$ and then decreased until the end of the storage period. This group had higher SOD activity, as compared to all other treatments (Figure 5(a)).

3.6.2. Catalase (CAT). CAT activity remained higher in $\mathrm{T} 5$ (100 $\mu \mathrm{M}$ MT for $120 \mathrm{~min})$. The activity of CAT in this group first showed a decline, reaching its minimum value after $14 \mathrm{~d}$ and again increasing after $21 \mathrm{~d}$, followed by another decrease after $28 \mathrm{~d}$ (Figure 5(b)).

3.6.3. Lipoxygenase (LOX). An increased LOX activity was seen up to $14 \mathrm{~d}$, which then declined in all groups. T5 $(100 \mu \mathrm{M}$ MT for $120 \mathrm{~min})$ maintained a low LOX activity throughout storage (Figure 5(c)).

\section{Discussion}

The postharvest storage of mango fruit at low temperature may be an option to ensure its extended availability, but conditions must be carefully controlled, since the development of CI is a major constrain to this practice. Previous studies have reported alleviation of CI when concentrations of MT similar to the ones used here were applied to various fruits, such as peach with $100 \mu \mathrm{M}$ [22], tomato with 100 and
$200 \mu \mathrm{M}$ [39], and pomegranate with $100 \mu \mathrm{M}$ MT [40]. In line with these studies, our results showed that a $100 \mu \mathrm{M}$ MT for 120 min treatment (T5) had a significant influence on the chilling tolerance of mango fruit. However, it should be noted that each combination of concentration and dipping duration had a particular impact on the results.

The relationship between CI and ethylene is complex, with some inconsistencies reported in various climacteric and nonclimacteric fruits [41]. For example, the severity of CI signs when fruits were reconditioned at room temperature after cold storage has been correlated with a steep rise in ethylene production [42]. In contrast, the promotion of ethylene production subsequent to an ethrel application resulted in the reduction of CI in mango fruits [43]. MT can apparently promote ethylene production in tomatoes stored at $15^{\circ} \mathrm{C}$ when administered at $50 \mu \mathrm{M}$ for $2 \mathrm{~h}$ [18] whereas suppression of ethylene production was reported in mango when $50 \mu \mathrm{M}$ MT was administered for $1 \mathrm{~h}$ [25], as well as in banana fruit at 200 and $500 \mu \mathrm{M}$ when administered for $2 \mathrm{~h}$ at $25^{\circ} \mathrm{C}$ [17]. These contrasting results may be explained by considering $\mathrm{MT}$ as a regulator of two intrinsically linked processes, i.e., ripening and senescence [19]. Ripening was positively regulated, while senescence was negatively regulated with MT treatments. Such a mode of action of ethylene after MT treatment needs further investigation, but it is likely that it is dependent on cultivar, concentration, immersion duration, storage conditions, etc. Additionally, and in line with the studies of $\mathrm{Hu}$ et al. [17] on banana fruit and Liu et al. [25] on mango fruit, our results also show that MT treatment significantly inhibited ethylene production. The minimum ethylene production in T5 $(100 \mu \mathrm{M}$ MT for $120 \mathrm{~min}$ ) was correlated with minimum CI signs and maximum quality maintenance for up to $28 \mathrm{~d}$ (Figure 1(a)). 


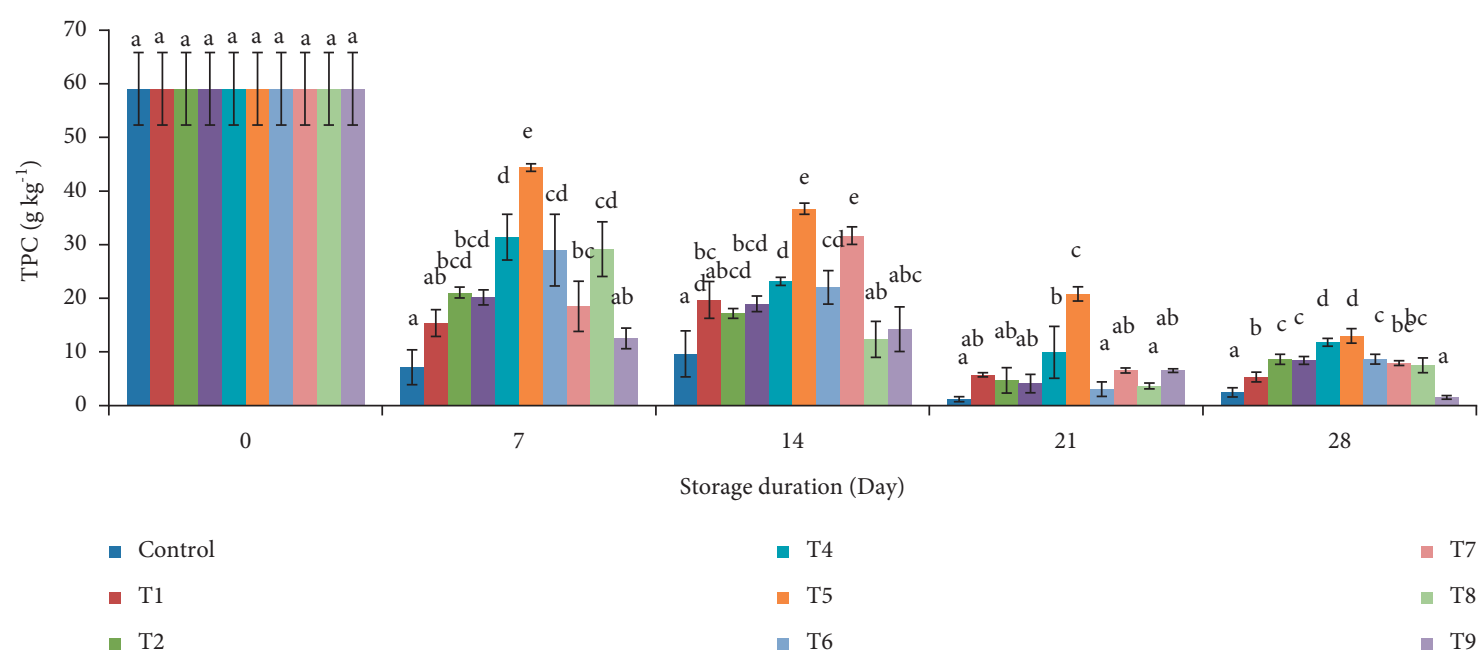

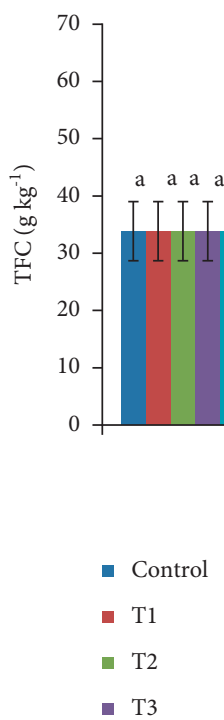

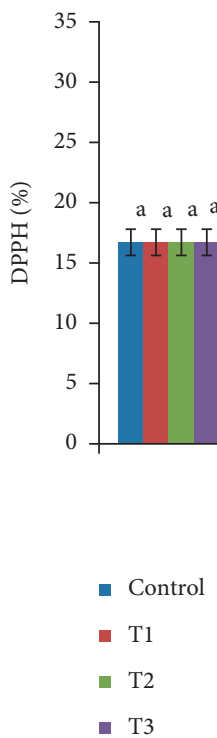

(a)

(b)

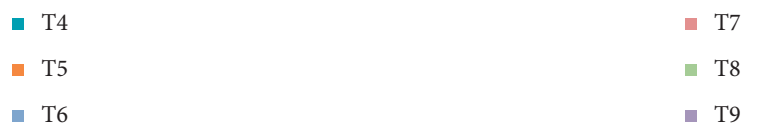




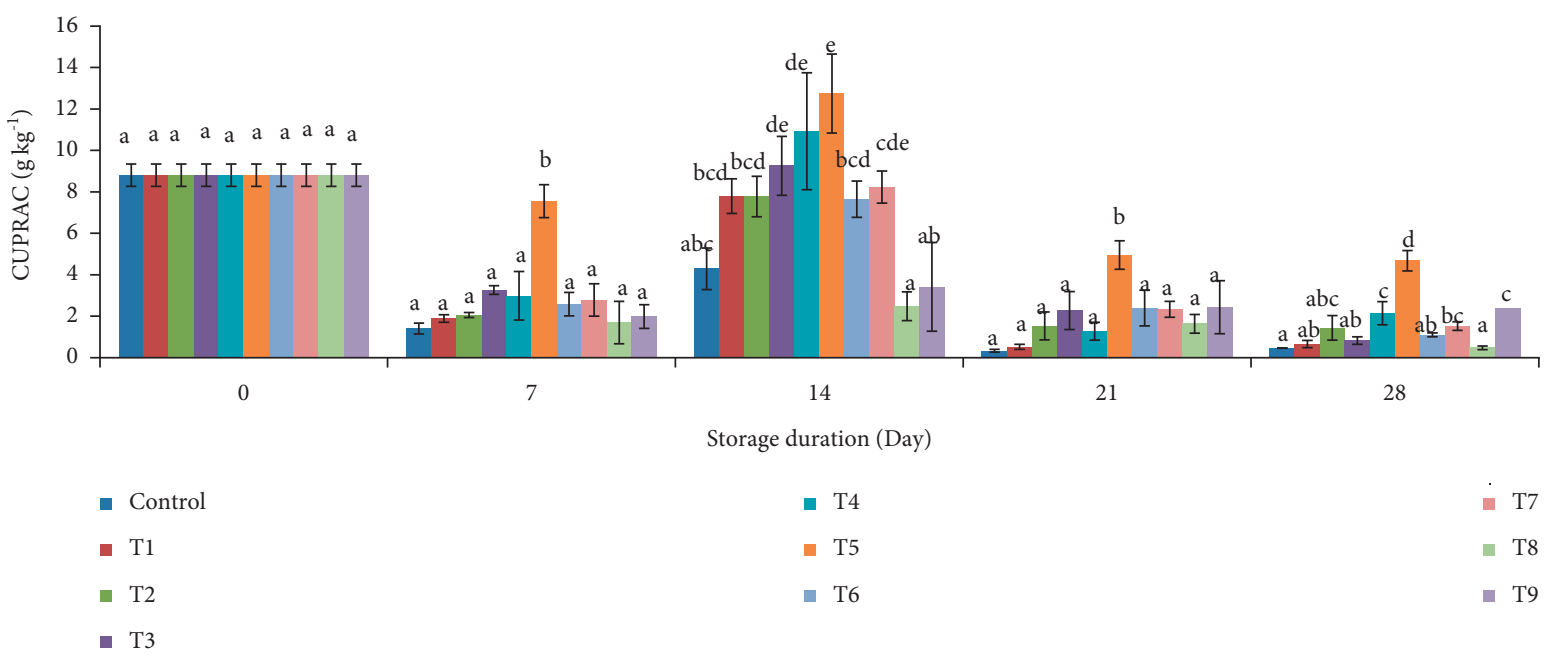

(d)

Figure 4: (a) Total phenolic content (TPC), (b) total flavonoid content (TFC), (c) 2,2-diphenyl-1-picrylhydrazyl (DPPH), and (d) cupric reducing antioxidant power (CUPRAC) of pulp of mango cv. "Dashehari" treated with melatonin (MT), followed by low-temperature storage at $5 \pm 1^{\circ} \mathrm{C}$. Measurements were taken every $7 \mathrm{~d}$ of storage, followed by a $3 \mathrm{~d}$ of shelf life at room temperature. Each value is the mean of three replicates; vertical bars indicate the standard error. Different lowercase letters on the same storage period indicate a significant difference $(p<0.05)$ according to Duncan's multiple range test. The abbreviated treatment details: 0 (control), $50 \mu \mathrm{M}$ for $90 \mathrm{~min}(\mathrm{~T} 1), 50 \mu \mathrm{M}$ for $120 \mathrm{~min}$ (T2), $50 \mu \mathrm{M}$ for $150 \mathrm{~min}$ (T3), $100 \mu \mathrm{M}$ for $90 \min$ (T4), $100 \mu \mathrm{M}$ for $120 \min$ (T5), $100 \mu \mathrm{M}$ for $150 \min$ (T6), $150 \mu \mathrm{M}$ for $90 \mathrm{~min}$ (T7), $150 \mu \mathrm{M}$ for $120 \mathrm{~min}$ (T8), and $150 \mu \mathrm{M}$ for $150 \mathrm{~min}$ (T9).

The reduced activities of ACC synthase (ACS) and ACC oxidase (ACO), as well as transcription of the MaACS1 and $M a A C O 1$, may explain the suppressed production of ethylene in MT-treated mangoes [17].

Respiration rate in T5 $(100 \mu \mathrm{M}$ MT for $120 \mathrm{~min})$ was reduced, in accordance with the study of Gao et al. [12], where peach fruits were treated with $100 \mu \mathrm{M}$ MT for $10 \mathrm{~min}$. Similar to our study, a postharvest application of nitric oxide $\left(10,20\right.$, and $\left.40 \mu \mathrm{L} \mathrm{L}^{-1}\right)$ alleviated CI in mango fruit, by inhibiting respiration rate and ethylene production [5]. During ripening, carbohydrates are converted into simple sugars, which results in an increase in TSS [44]. Furthermore, consumption of organic acids by various metabolic processes leads to a decrease in TA, with a subsequent increase in $\mathrm{pH}$ and TSS/TA ratio. However, mango fruits in T5 $(100 \mu \mathrm{M}$ MT for $120 \mathrm{~min})$ maintained a significantly high TA and firmness, along with low weight loss, $\mathrm{pH}$, TSS, and TSS/ TA ratio. These results indicate that MT delayed senescence and preserved the quality of treated fruits. Our findings are therefore in accordance with previous studies done on peach [12] and pear [15], where $100 \mu \mathrm{M}$ MT had positive effects against senescence.

A reduced activity of the enzymatic and nonenzymatic antioxidant system, progressive ripening, biotic or abiotic stress, and other conditions will lead to disruption of cellular homeostasis, which leads to oxidative stress. In line with the previous studies done by Gao et al. [12] on peach fruit and Zhai et al. [15] on pear, our data shows that T5 $(100 \mu \mathrm{M}$ MT for $120 \mathrm{~min}$ ) applied to mango fruits maintained significantly higher SOD and CAT activities, which apparently mitigated cellular damage due to reactive oxygen species (ROS). SOD and CAT are key players in scavenging ROS since their combined activities dismutate $\mathrm{O}_{2}{ }^{--}$into $\mathrm{H}_{2} \mathrm{O}_{2}$ (SOD), which is then converted into $\mathrm{H}_{2} \mathrm{O}$ and molecular oxygen (CAT) [45]. Furthermore, MT treatment also maintained a significantly higher concentration of nonenzymatic antioxidants, i.e., ascorbic acid, TPC, and TFC. As a result of significantly higher enzymatic and nonenzymatic antioxidant systems, the total AA (DPPH and CUPRAC assays) was also higher in T5 $(100 \mu \mathrm{M}$ MT for $120 \mathrm{~min})$. This maintenance in AA is in agreement with previous results obtained by Liu et al. [46] in strawberry fruit, Zhang et al. [47] in litchi fruit, and Rastegar et al. [20] in mango fruit at a temperature of $15^{\circ} \mathrm{C}$.

LOX is a lipid-oxidizing enzyme, which can contribute to the peroxidation of membrane lipids in concert with ROS. The process of lipid peroxidation will result in the formation of lipid hydroperoxides from polyunsaturated fatty acids found in the cellular membrane, thereby leading to a loss of membrane integrity [48]. This phenomenon affects not only compartmentalization but also the activities of proteins related to signaling, energy generation systems, and various other processes. MDA is an end product of lipid peroxidation and is one of the most commonly studied indicators of this process [49]. Our data showed that mango fruit treated with $100 \mu \mathrm{M}$ MT for $120 \mathrm{~min}$ (T5) had a significantly lower LOX activity and MDA concentration, in comparison to all other treatments, which is in accordance with previous studies done on peach [12], pear [15], and strawberry [46].

Moreover, the plasma membrane is permeable for the entry of exogenously applied MT application into the cell and leads to enhancement of endogenous MT level [50]. Raised level of endogenous MT initiates a cascade of events (auxin, ethylene, and mitogen-activated protein kinase, MAPK) due to the signaling property of MT during stressful conditions [51]. MT activates signaling pathways namely, gibberellic acid (GA), salicylic acid (SA), and abscisic acid (ABA). These 


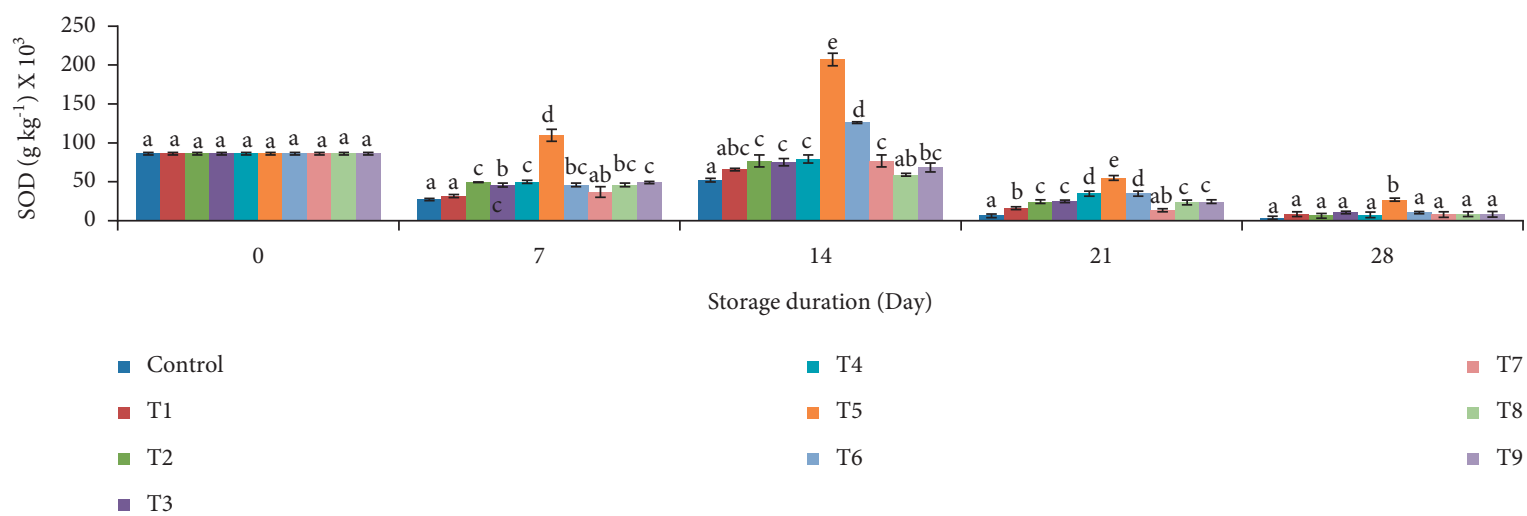

(a)

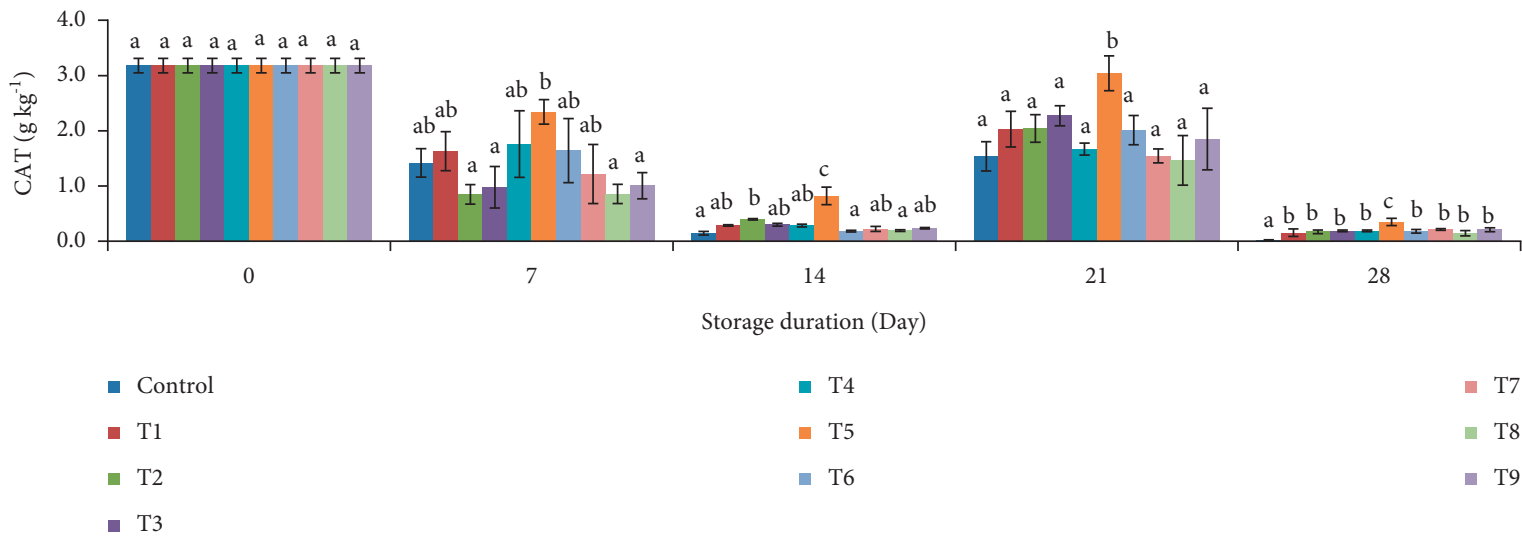

(b)

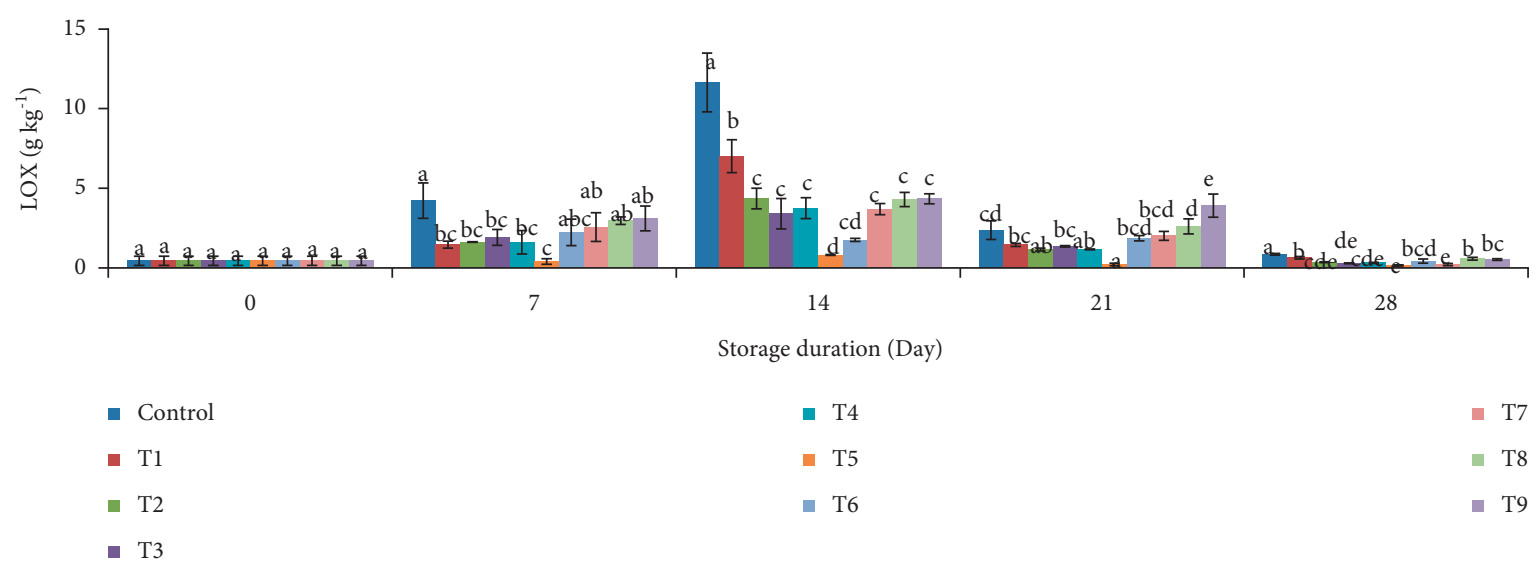

(c)

FIgURe 5: (a) Superoxide dismutase (SOD), (b) catalase (CAT), and (c) lipoxygenase (LOX) activities of mango cv. "Dashehari" treated with melatonin (MT), followed by low-temperature storage at $5 \pm 1^{\circ} \mathrm{C}$. Measurements were taken every $7 \mathrm{~d}$ of storage, followed by a $3 \mathrm{~d}$ of shelf life at room temperature. Each value is the mean of three replicates; vertical bars indicate the standard error. Different lowercase letters on the same storage period indicate a significant difference $(p<0.05)$ according to Duncan's multiple range test. The abbreviated treatment details: 0 (control), $50 \mu \mathrm{M}$ for $90 \mathrm{~min}$ (T1), $50 \mu \mathrm{M}$ for $120 \mathrm{~min}$ (T2), $50 \mu \mathrm{M}$ for $150 \mathrm{~min}$ (T3), $100 \mu \mathrm{M}$ for $90 \mathrm{~min}$ (T4), $100 \mu \mathrm{M}$ for $120 \mathrm{~min}$ (T5), $100 \mu \mathrm{M}$ for $150 \mathrm{~min}$ (T6), $150 \mu \mathrm{M}$ for $90 \mathrm{~min}$ (T7), $150 \mu \mathrm{M}$ for $120 \mathrm{~min}$ (T8), and $150 \mu \mathrm{M}$ for $150 \mathrm{~min}$ (T9).

activities of MT lead to the modulation of physiological characteristics of a cell that persists in its survival under adverse situations of stress [50]. Apparently, apart from its direct antioxidative behavior, metabolites of MT (3hydroxymelatonin, N1-acetyl-N2-formayl-5-methoxykynuramine, and 2-hydroxymelatonin) also act in the removal of ROS and reactive nitrogen species (RNS) [52], which eliminate the necessity of exact recovering pathway in order to have redox cycle accomplishment [53]. Furthermore, chloroplast and mitochondria were regarded as the site of MT synthesis in plants that relates its efficacy in free radical removal and proficiency in electron transport chain promotion [54], which directly related it to the higher maintenance of energy status of cell and plasma membrane stability. 
However, all these discoveries are on the limited edge in postharvest fruits and vegetables in comparison with plant and animal cells. But there are studies, which have provided results for the maintenance of the antioxidant system with MT application in postharvest fruit and vegetables under stressful conditions (cold stress in the present study) as mentioned above in line with the previous studies done with tomato [39], pomegranate [40], sapota [55], strawberry [13], and peach [22] fruit. Additionally, cold stress tolerance is developed through enhanced activity of enzymes namely, $\mathrm{H}$-ATPase, Ca-ATPase, and cytochrome $c$ oxidase that will indirectly lead to maintenance of a high ratio of unsaturated/ saturated fatty acid and thereby low MDA production [40]. Furthermore, treatment of MT has promoted the synthesis of polyamine [56], NO [23], and proline [57] in order to confer CI.

\section{Conclusions}

A $100 \mu \mathrm{M}$ melatonin treatment administered for $120 \mathrm{~min}$ maintained the postharvest quality parameters of mangoes cv. "Dashehari" that were cold-stored at $5 \pm 1{ }^{\circ} \mathrm{C}$ for $28 \mathrm{~d}$. This was due to higher membrane integrity, which resulted from low malondialdehyde production and lipoxygenase activity. The same treatment also delayed senescence through an inhibited ethylene production and respiration rate, parameters that are closely related to the natural ripening process. Low oxidative stress was apparently due to stimulating the enzymatic and nonenzymatic antioxidant systems of mango fruit. Thus, a melatonin treatment alleviated the signs of chilling injury in mangoes. Optimization studies may be required to determine ideal concentrations and times in other fruits.

\section{Data Availability}

Data will be made available on request to the corresponding author.

\section{Conflicts of Interest}

The authors declare that there are no conflicts of interest.

\section{Authors' Contributions}

Renu Bhardwaj contributed to the setup of the experiment, data collection, analysis of the data interpretation, and drafting of the article. Sunil Pareek was responsible for the formalization of concept, experimental design, interpretation, reviewing the manuscript, supervision, and coordination. Sarvanan Mani assisted in performing some sets of experiments. G.A. Gonzalez-Aguilar and J. Abraham Domínguez-Avila edited the manuscript and improve the overall presentation.

\section{Acknowledgments}

The authors are thankful to the National Institute of Food Technology Entrepreneurship and Management (NIFTEM), India, for providing facilities and support. Additionally, they would like to thank Ankur Kumar, lab in-charge, Central Instrumentation Laboratory, NIFTEM, for providing his constant support throughout the work.

\section{References}

[1] R. N. Tharanathan, H. M. Yashoda, and T. N. Prabha, "Mango (Mangifera indica L.), "the king of fruits"-an overview," Food Reviews International, vol. 22, no. 2, pp. 95-123, 2006.

[2] S. Nair, Z. Singh, and S. C. Tan, "Aroma volatiles emission in relation to chilling injury in "Kensington Pride" mango fruit," The Journal of Horticultural Science and Biotechnology, vol. 78, no. 6, pp. 866-873, 2003.

[3] Z. Singh, R. K. Singh, V. A. Sane, and P. Nath, "Mangopostharvest biology and biotechnology," Critical Reviews in Plant Sciences, vol. 32, no. 4, pp. 217-236, 2013.

[4] S. M. Zahedi, M. S. Hosseini, M. Karimi, and A. Ebrahimzadeh, "Effects of postharvest polyamine application and edible coating on maintaining quality of mango (Mangifera indica L.) cv. Langra during cold storage," Food Sciences and Nutrition, vol. 7, no. 2, pp. 433-441, 2019.

[5] S. S. Zaharah and Z. Singh, "Postharvest nitric oxide fumigation alleviates chilling injury, delays fruit ripening and maintains quality in cold-stored "Kensington Pride" mango," Postharvest Biology and Technology, vol. 60, no. 3, pp. 202-210, 2011.

[6] S. Nair and Z. Singh, “"Pre-storage ethrel dip reduces chilling injury, enhances respiration rate, ethylene production and improves fruit quality of 'Kensington' mango," Journal of Food Agriculture and Environment, vol. 1, pp. 93-97, 2003.

[7] Z. Zhang, Q. Zhu, M. Hu et al., "Low-temperature conditioning induces chilling tolerance in stored mango fruit," Food Chemistry, vol. 219, pp. 76-84, 2017.

[8] G. A. González-Aguilar, J. Fortiz, R. Cruz, R. Baez, and C. Y. Wang, "Methyl jasmonate reduces chilling injury and maintains postharvest quality of mango fruit," Journal of Agricultural and Food Chemistry, vol. 48, no. 2, pp. 515-519, 2000.

[9] Z.-S. Ding, S.-P. Tian, X.-L. Zheng, Z.-W. Zhou, and Y. Xu, "Responses of reactive oxygen metabolism and quality in mango fruit to exogenous oxalic acid or salicylic acid under chilling temperature stress," Physiologia Plantarum, vol. 130, no. 1, pp. 112-121, 2007.

[10] J. Fan, Y. Xie, Z. Zhang, and L. Chen, "Melatonin: a multifunctional factor in plants," International Journal of Molecular Sciences, vol. 19, no. 5, p. 1528, 2018.

[11] A. Galano and R. J. Reiter, "Melatonin and its metabolites vs oxidative stress: from individual actions to collective protection," Journal of Pineal Research, vol. 65, no. 1, p. e12514, 2018.

[12] H. Gao, Z. K. Zhang, H. K. Chai et al., "Melatonin treatment delays postharvest senescence and regulates reactive oxygen species metabolism in peach fruit," Postharvest Biology and Technology, vol. 118, pp. 103-110, 2016.

[13] M. S. Aghdam and J. R. Fard, "Melatonin treatment attenuates postharvest decay and maintains nutritional quality of strawberry fruits (Fragaria $\times$ anannasa cv. Selva) by enhancing GABA shunt activity," Food Chemistry, vol. 221, pp. 16501657, 2017.

[14] M. S. Aghdam, A. Jannatizadeh, Z. Luo, and G. Paliyath, "Ensuring sufficient intracellular ATP supplying and friendly extracellular ATP signaling attenuates stresses, delays senescence and maintains quality in horticultural crops during postharvest life," Trends in Food Science \& Technology, vol. 76, pp. 67-81, 2018. 
[15] R. Zhai, J. Liu, F. Liu et al., "Melatonin limited ethylene production, softening and reduced physiology disorder in pear (Pyrus communis L.) fruit during senescence," Postharvest Biology and Technology, vol. 139, pp. 38-46, 2018.

[16] M. S. Aghdam, Z. Luo, A. Jannatizadeh et al., "Employing exogenous melatonin applying confers chilling tolerance in tomato fruits by upregulating ZAT2/6/12 giving rise to promoting endogenous polyamines, proline, and nitric oxide accumulation by triggering arginine pathway activity," Food Chemistry, vol. 275, pp. 549-556, 2019.

[17] W. Hu, H. Yang, W. Tie et al., "Natural variation in banana varieties highlights the role of melatonin in postharvest ripening and quality," Journal of Agricultural and Food Chemistry, vol. 65, no. 46, pp. 9987-9994, 2017.

[18] Q. Sun, N. Zhang, J. Wang et al., "Melatonin promotes ripening and improves quality of tomato fruit during postharvest life," Journal of Experimental Botany, vol. 66, no. 3, pp. 657-668, 2015.

[19] L. Xu, Q. Yue, G. Xiang, F. Bian, and Y Yao, "Melatonin promotes ripening of grape berry via increasing the levels of $\mathrm{ABA}, \mathrm{H} 2 \mathrm{O} 2$, and particularly ethylene," Horticulture Research, vol. 5, pp. 41-11, 2018.

[20] S. Rastegar, H. H. Khankahdani, and M. Rahimzadeh, "Effects of melatonin treatment on the biochemical changes and antioxidant enzyme activity of mango fruit during storage," Scientia Horticulturae, vol. 259, no. 108835, 2020.

[21] S. Cao, J. Shao, L. Shi et al., "Melatonin increases chilling tolerance in postharvest peach fruit by alleviating oxidative damage," Scientific Reports, vol. 8, pp. 806-811, 2018.

[22] H. Gao, Z. Lu, Y. Yang et al., "Melatonin treatment reduces chilling injury in peach fruit through its regulation of membrane fatty acid contents and phenolic metabolism," Food Chemistry, vol. 245, pp. 659-666, 2018.

[23] M. S. Aghdam, Z. Luo, L. Li, A. Jannatizadeh, J. R. Fard, and F. Pirzad, "Melatonin treatment maintains nutraceutical properties of pomegranate fruits during cold storage," Food Chemistry, vol. 303, p. 125385, 2020.

[24] L. L. Zhu, H. L. Hu, S. F. Luo, Z. X. Wu, and P. X. Li, "Melatonin delaying senescence of postharvest broccoli by regulating respiratory metabolism and antioxidant activity," Transactions of the Chinese Society of Agricultural Engineering, vol. 34, pp. 300-308, 2018.

[25] C. Liu, H. Zheng, K. Sheng, W. Liu, and L. Zheng, "Effects of melatonin treatment on the postharvest quality of strawberry fruit," Postharvest Biology and Technology, vol. 139, pp. 47-55, 2018.

[26] A. Concellón, M. Añón, and A. Chaves, "Effect of chilling on ethylene production in eggplant fruit," Food Chemistry, vol. 92, no. 1, pp. 63-69, 2005.

[27] W. George and J. R. Latimer, Official Method of Analysis of AOAC, AOAC, Gaithersburg, MD, USA, 21st edition, 2019.

[28] A. U. Malik and S. Zora, "Pre-storage application of polyamines improves shelf-life and fruit quality of mango," The Journal of Horticultural Science and Biotechnology, vol. 80, no. 3, pp. 363-369, 2005.

[29] M. Jincy, M. Djanaguiraman, P. Jeyakumar, K. S. Subramanian, S. Jayasankar, and G. Paliyath, "Inhibition of phospholipase $\mathrm{D}$ enzyme activity through hexanal leads to delayed mango (Mangifera indica L.) fruit ripening through changes in oxidants and antioxidant enzymes activity," Scientia Horticulturae, vol. 218, pp. 316-325, 2017.

[30] L. A. Castro-Concha, J. Tuyub-Che, A. Moo-Mukul, F. A. Vazquez-Flota, and M. L. Miranda-Ham, "“Antioxidant capacity and total phenolic content in fruit tissues from accessions of Capsicum chinense Jacq. (Habanero pepper) at different stages of ripening," The Scientific World Journal, vol. 2014, Article ID 809073, 5 pages, 2014.

[31] V. L. Singleton and J. A. Rossi, "Colorimetry of total phenolics with phosphomolybdic-phosphotungstic acid reagents," American Journal of Enology and Viticulture, vol. 16, pp. 144-158, 1965.

[32] C. C. Chang, M. H. Yang, H. M. Wen, and J. C. Chern, "Estimation of total flavonoid content in propolis by two complementary colorimetric methods," Journal of Food and Drug Analysis, vol. 10, no. 3, 2002.

[33] J. A. Larrauri, C. Sánchez-Moreno, and F. Saura-Calixto, "Effect of temperature on the free radical scavenging capacity of extracts from red and white grape pomace peels," Journal of Agricultural and Food Chemistry, vol. 46, no. 7, pp. 26942697, 1998.

[34] S. A. Arscott and S. A. Tanumihardjo, "Carrots of many colors provide basic nutrition and bioavailable phytochemicals acting as a functional food," Comprehensive Reviews in Food Science and Food Safety, vol. 9, no. 2, pp. 223-239, 2010.

[35] Y. Kono, "Generation of superoxide radical during autoxidation of hydroxylamine and an assay for superoxide dismutase," Archives of Biochemistry and Biophysics, vol. 186, no. 1, pp. 189-195, 1978.

[36] H. Aebi, "Catalase," in Methods of Enzymatic AnalysisAcademic Press, Cambridge, MA, USA, 1974.

[37] J. F. Todd, G. Paliyath, and J. E. Thompson, "Characteristics of a membrane-associated lipoxygenase in tomato fruit," Plant Physiology, vol. 94, no. 3, pp. 1225-1232, 1990.

[38] M. M. Bradford, "A rapid and sensitive method for the quantitation of microgram quantities of protein utilizing the principle of protein-dye binding," Analytical Biochemistry, vol. 72, no. 1-2, pp. 248-254, 1976.

[39] F. Azadshahraki, B. Jamshidi, and S. Mohebbi, "Postharvest melatonin treatment reduces chilling injury and enhances antioxidant capacity of tomato fruit during cold storage," Advances in Horticultural Science, vol. 32, pp. 299-309, 2018.

[40] A. Jannatizadeh, "Exogenous melatonin applying confers chilling tolerance in pomegranate fruit during cold storage," Scientia Horticulturae, vol. 246, pp. 544-549, 2019.

[41] C. B. Watkins and W. B. Miller, "1-Methylcyclopropene (1MCP) based technologies for storage and shelf-life extension," Acta Horticulturae, vol. 687, no. 687, pp. 201-208, 2005.

[42] L. Sevillano, M. T. Sanchez-Ballesta, F. Romojaro, and F. B. Flores, "Physiological, hormonal and molecular mechanisms regulating chilling injury in horticultural species. Postharvest technologies applied to reduce its impact," Journal of the Science of Food and Agriculture, vol. 89, no. 4, pp. 555-573, 2009.

[43] S. Suresh Nair, Z. Zora Singh, and S. C. Tan, "Chilling injury in relation to ethylene biosynthesis in "Kensington Pride" mango fruit," The Journal of Horticultural Science and Biotechnology, vol. 79, no. 1, pp. 82-90, 2004.

[44] F. Kittur, N. Saroja, R. Habibunnisa, and R. Tharanathan, "Polysaccharide-based composite coating formulations for shelf-life extension of fresh banana and mango," European Food Research and Technology, vol. 213, no. 4-5, pp. 306-311, 2001.

[45] R. Mittler, "Oxidative stress, antioxidants and stress tolerance," Trends in Plant Science, vol. 7, no. 9, pp. 405-410, 2002.

[46] S. Liu, H. Huang, D. J. Huber, Y. Pan, X. Shi, and Z. Zhang, "Delay of ripening and softening in "Guifei" mango fruit by postharvest application of melatonin," Postharvest Biology and Technology, vol. 163, p. 111136, 2020. 
[47] Y. Zhang, D. J. Huber, M. Hu et al., "Delay of postharvest browning in litchi fruit by melatonin via the enhancing of antioxidative processes and oxidation repair," Journal of Agricultural and Food Chemistry, vol. 66, no. 28, pp. 74757484, 2018.

[48] R. L. Shewfelt and B. A. Del Rosario, "The role of lipid peroxidation in storage disorders of fresh fruits and vegetables," HortScience, vol. 35, no. 4, pp. 575-579, 2000.

[49] R. S. Dhindsa, P. L. Plumb-Dhindsa, and D. M. Reid, "Leaf senescence and lipid peroxidation: effects of some phytohormones, and scavengers of free radicals and singlet oxygen," Physiologia Plantarum, vol. 56, no. 4, pp. 453-457, 1982.

[50] S. K. Bose and P. Howlader, "Melatonin plays multifunctional role in horticultural crops against environmental stresses: a review," Environmental and Experimental Botany, vol. 176, p. 104063, 2020.

[51] C. Li, P. Wang, Z. Wei et al., "The mitigation effects of exogenous melatonin on salinity-induced stress in Malus hupehensis," Journal of Pineal Research, vol. 53, no. 3, pp. 298-306, 2012.

[52] D.-X. Tan, L. C. Manchester, M. P. Terron, L. J. Flores, and R. J. Reiter, "One molecule, many derivatives: a never-ending interaction of melatonin with reactive oxygen and nitrogen species?" Journal of Pineal Research, vol. 42, no. 1, pp. 28-42, 2007.

[53] M. I. Rodriguez-Naranjo, M. L. Moyá, E. Cantos-Villar, and M. C. Garcia-Parrilla, "Comparative evaluation of the antioxidant activity of melatonin and related indoles," Journal of Food Composition and Analysis, vol. 28, no. 1, pp. 16-22, 2012.

[54] A. K. Parida and A. B. Das, "Salt tolerance and salinity effects on plants: a review," Ecotoxicology and Environmental Safety, vol. 60 , no. 3, pp. 324-349, 2005.

[55] A. Mirshekari, B. Madani, E. M. Yahia, J. B. Golding, and S. H. Vand, "Postharvest melatonin treatment reduces chilling injury in sapota fruit," Journal of the Science of Food and Agriculture, vol. 100, no. 5, pp. 1897-1903, 2020.

[56] R. Bhardwaj, S. Pareek, C. Saravanan, and E. M. Yahia, " $\gamma$ Contribution of pre-storage melatonin application to chilling tolerance of some mango fruit cultivars and relationship with polyamines metabolism and $\gamma$-aminobutyric acid shunt pathway," Environmental and Experimental Botany, vol. 194, p. 104691, 2022.

[57] R. Bhardwaj, S. Pareek, G. A. González-Aguilar, and J. A. Domínguez-Avila, "Changes in the activity of prolinemetabolising enzymes is associated with increased cultivardependent chilling tolerance in mangos, in response to prestorage melatonin application," Postharvest Biology and Technology, vol. 182, p. 111702, 2021. 